\title{
The Utilization-Adjusted Output Gap: Is the Russian Economy Overheating?
}

Nienke Oomes and Oksana Dynnikova 



\title{
IMF Working Paper
}

European Department and Policy Development and Review Departments

\section{The Utilization-Adjusted Output Gap: Is the Russian Economy Overheating?}

\author{
Prepared by Nienke Oomes and Oksana Dynnikova ${ }^{1}$ \\ Authorized for distribution by Lorenzo Figliuoli and Patricia Alonso-Gamo
}

March 2006

\begin{abstract}

\section{This Working Paper should not be reported as representing the views of the IMF.} The views expressed in this Working Paper are those of the author(s) and do not necessarily represent those of the IMF or IMF policy. Working Papers describe research in progress by the author(s) and are published to elicit comments and to further debate.
\end{abstract}

This paper estimates the output gap in Russia using a utilization-adjusted production function approach, which we argue is preferable to traditional output gap methods. The approach amounts to (1) using available surveys to estimate the "natural rates" of capacity and labor utilization above which inflation begins to accelerate; (2) estimating a production function with utilization-adjusted capital and labor inputs; and (3) defining potential output as the level of output obtained when both capital and labor are at their estimated natural rates. The results suggest that the output gap in Russia was negative between 1999 and 2003, but may have recently become positive, thus contributing to inflationary pressures.

JEL Classification Numbers: D24, E31, E32, P24

Keywords: Output gap, capacity utilization, natural rate, Phillips curve, Russia

Author(s) E-Mail Address: noomes@imf.org; odynnikova@imf.org

\footnotetext{
${ }^{1}$ For useful comments and suggestions on an earlier draft, the authors are grateful to the institutions responsible for the capacity utilization surveys discussed in this paper (Rosstat, REB, IET, and CEA), participants in seminars held at the IMF and the Ministry of Finance of the Russian Federation, and Vladimir Bessonov, Andreas Billmeier, Lorenzo Figliuoli, Neven Mates, Antonio Spilimbergo, Emil Stavrev, Poul Thomsen, and Harm Zebregs. The authors alone are solely responsible for any errors.
} 


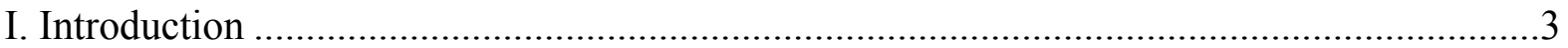

II. The Nonaccelerating Inflation Rate of Factor Utilization ..............................................5

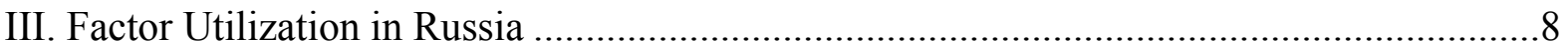

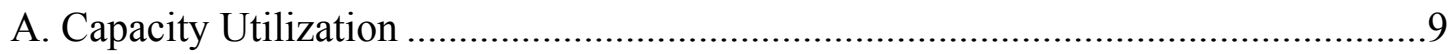

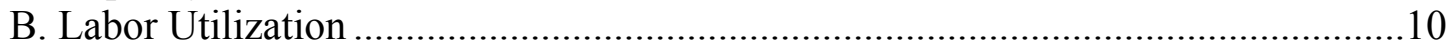

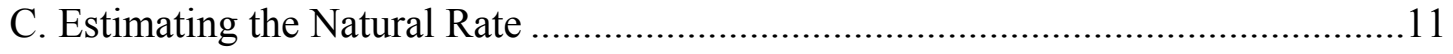

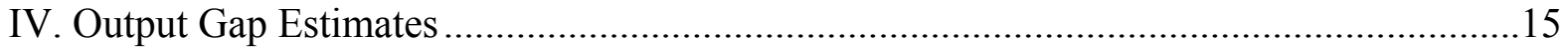

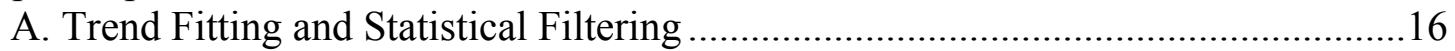

B. Production Function Approach .................................................................. 16

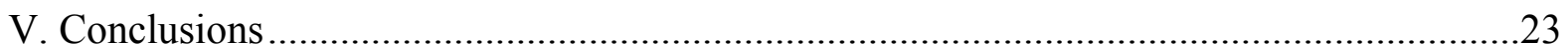

Appendices

I. Characteristics and Methodology of Capacity Utilization Surveys............................ 24

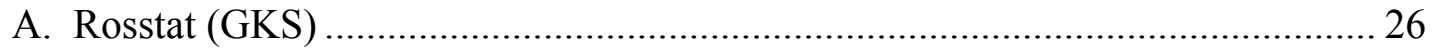

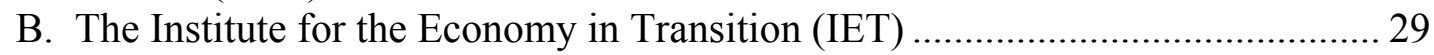

C. Russian Economic Barometer (REB) ....................................................... 31

D. The Center for Economic Analysis (CEA) …................................................. 34

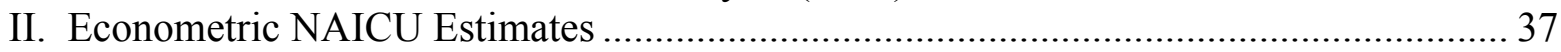

III. Statistical Methods for Estimating the Output Gap .............................................. 40

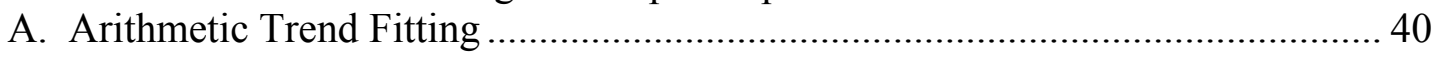

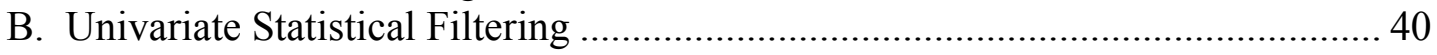

Appendix Tables

A1. Capacity Utilization Survey Characteristics ......................................................... 24

A2. Population and Sample Size Distribution of Russian Industrial Enterprises, 2003 ...... 24

B1. NAICU Estimates based on REB Capacity Utilization Survey …............................. 37

B2. NAICU Estimates based on IET Capacity Utilization Survey................................... 38

B3. NAICU Estimates based on CEA Capacity Utilization Survey ................................ 39

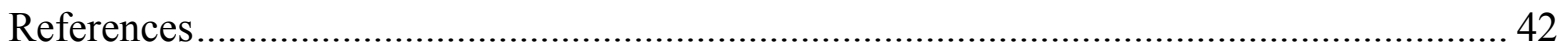

Text Table

1. Estimated Natural and Actual Capacity Utilization Rates ....................................... 14

Figures

1. Output Gap Estimates Using Arithmetic Trends and Statistical Filters ....................... 18

2. Output Gap Estimates Based on the Production Function Approach ........................... 22 


\section{INTRODUCTION}

Inflation in Russia appears to be entrenched at double-digit levels. After falling from about 25 percent in mid-2001 to almost 10 percent in mid-2004, the year-on-year headline inflation rate has picked up since then. While this pickup in headline (total CPI) inflation has partly reflected temporary factors (unseasonably high food prices and administered price hikes), even core inflation-which excludes such factorshas been entrenched at above 10 percent

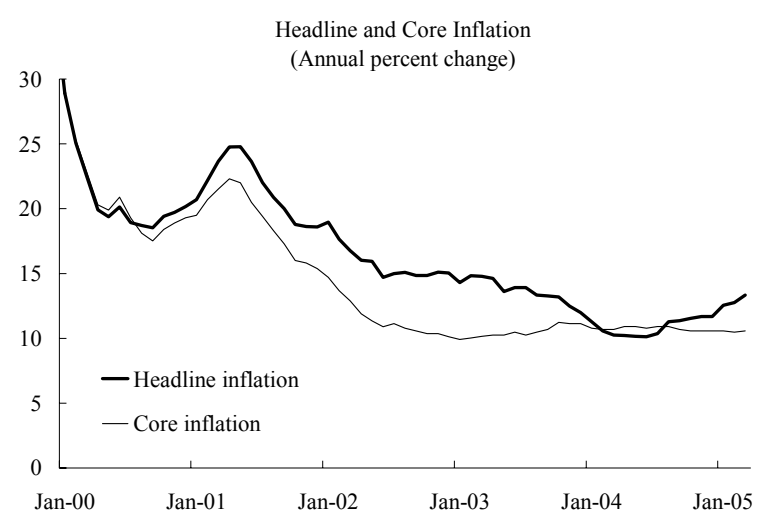
since mid-2002. Bringing down inflation to single digits thus appears difficult.

A possible explanation for the failure of Russian inflation to come down is that the Russian economy is facing increasing supply-side constraints in goods and labor markets, creating excess demand and, hence, inflationary pressures. Supply-side constraints in goods markets are likely to have arisen because of insufficient investment: gross fixed investment in Russia has been a mere 18 percent of GDP, which is less than in most other transition countries. ${ }^{2}$ Supply-side constraints in labor markets, on the other hand, appear to be the result of a lack of interregional labor mobility, an indication of which is the large variation in regional unemployment rates and incomes (Kwon and Spilimbergo, 2005; Andrienko and Guriev, 2004).

This paper finds evidence that supply-side constraints may indeed be emerging in Russia. More specifically, we find that capacity and labor utilization were, by end-2004, near or above their "natural" rates, above which they contribute to inflationary pressures. ${ }^{3} \mathrm{We}$ arrive at this finding by estimating the nonaccelerating inflation rate of capacity utilization (NAICU) and the nonaccelerating inflation rate of labor utilization (NAILU), that is, the "natural" rates of capacity and labor utilization, above which inflation is expected to

\footnotetext{
${ }^{2}$ Between 2000 and 2004, the investment share in Russia was roughly 18 percent of GDP, while it was around 23 percent in Central and Eastern European economies, and increased from 17 to 23 percent in other member countries of the Commonwealth of Independent States (CIS) . In 2004, the only transition countries with lower investment shares than Russia were Uzbekistan (10 percent), Tajikistan (14 percent), and Macedonia (17 percent), while at least 22 transition countries had higher investment shares than Russia. The transition countries with the highest investment shares were the Czech and Slovak Republics (27 percent), Estonia (28 percent), and Azerbaijan (55 percent).

${ }^{3}$ A similar conclusion was drawn by Gavrilenkov (2003, p. 18), who argued that "the growth mechanism that emerged after the 1998 crisis and contributed to an economic upturn is largely exhausted.... [T] his mechanism was based on increased capacity utilization, but after a number of straight years of growth, most sectors now lack spare capacity."
} 
accelerate. Our estimate for the NAICU for Russia ranges from 57 percent to 74 percent, depending on which of the available three surveys is used to estimate capacity utilization. Despite this large range, the NAICU is quite precisely estimated for each survey estimate, and is robust to the inclusion of lags and other inflation determinants. While we were unable to obtain a significant regression estimate of the NAILU, available survey data suggest that labor utilization has been approximately at its natural rate since 2000 .

The main contribution of this paper is that we combine our estimates of the NAICU and the NAILU into a "utilization-adjusted output gap," using a production function approach. The output gap is defined as the difference between actual output and potential output, in percent of potential output, and is a commonly used measure of the state of the business cycle. While the production function approach is one of the standard methods for estimating the output gap, the novelty of this paper is that we estimate a production function where both factors (capital and labor) are adjusted for their utilization rates. We thus define potential output as the level of output produced when factor utilization and total factor productivity are at their natural rates. If the output gap is negative - that is, utilization rates are below their natural rates - an increase in demand can be accommodated by an increase in factor utilization and, therefore, is not inflationary. If the output gap is positive, however, this implies that, in the short run, an increase in demand can be met only by letting existing production factors work overtime. This increases the cost of production; hence, inflationary pressures will build up. In the long run, total capacity can be increased by hiring additional labor and capital, thus lowering utilization rates and easing inflationary pressures.

We argue that our utilization-adjusted production function approach is preferable to traditional methods for estimating the output gap. In our view, traditional trend-fitting and filtering methods are not appropriate for a transition economy like Russia, since these methods do not adjust for utilization and assume, by construction, that the output gap has been zero on average. While the latter is a reasonable assumption for very long samples, it need not hold in any given short sample. The advantage of our utilization-adjusted production function approach is that no such assumption needs to be made. Indeed, we find that the output gap in Russia has been negative for most of the sample period.

Our utilization-adjusted production function approach suggests that the output gap in Russia has been closing rapidly since 1999 and may have already become positive. This implies that faster-than-potential growth can only be achieved at the cost of higher inflation. Our estimates thus suggest that, in order to reduce inflation and increase growth, macroeconomic policies and reforms should not focus on stimulating demand but, rather, on raising potential output growth by alleviating supply-side constraints.

Our results are subject to a number of caveats, and, therefore, should be interpreted with caution. First, it is difficult to estimate cyclical demand pressures in a transition economy that has had only a limited experience with business cycles. Second, our assessment that the economy is close to overheating is based on capacity and labor utilization data for the manufacturing sector, while utilization in other sectors may have been different. (However, utilization rates in the fuel and services sectors are also likely to have been high recently). 
Third, our Cobb-Douglas production function estimates depend on a number of assumptions that may be unrealistic. Fourth, several parameters used in this approach are imprecisely measured (notably, the capital stock, and capital and labor shares). Fifth, our finding that the output gap may have become positive in 2005 depends on the estimate of potential output growth, the determination of which deserves further research.

\section{The Nonaccelerating Inflation RATE OF FACtor Utilization}

We propose to measure supply-side constraints in Russia by estimating the nonaccelerating inflation rate of capacity utilization (NAICU) and the nonaccelerating inflation rate of labor utilization (NAILU). The concept of the NAICU (sometimes called NAIRCU) was first introduced by McElhattan (1978) and is similar to that of the nonaccelerating inflation rate of unemployment (NAIRU), in that it is related to the notion of a vertical long-run Phillips curve, as explained below. ${ }^{4}$ We are not aware of any previous papers that have used the concept of the NAILU.

To explain the concepts of NAICU and NAILU, we present a model of a simple economy in which prices are set by a simple mark-up equation:

$$
\pi_{t}=\varphi\left(\Delta w_{t}-\Delta a_{L, t}\right)+(1-\varphi)\left(\Delta r_{t}-\Delta a_{K, t}\right)
$$

where $\pi_{t}$ indicates the rate of core inflation, $\Delta w_{t}$ is the growth in the average wage level, $\Delta r_{t}$ is the rate of change in the cost of capital, and $\Delta a_{L, t}$ and $\Delta a_{K, t}$ denote the rates of change in labor productivity and capital productivity, respectively, so that $\Delta w_{t}-\Delta a_{L, t}$ measures the growth in unit labor costs, and $\Delta r_{t}-\Delta a_{K, t}$ measures the growth in unit capital costs. The parameter $\varphi \in[0,1]$ measures the relative contribution of unit labor costs to inflation, so that $1-\varphi$ measures the relative contribution of unit capital costs to inflation. ${ }^{5}$

Factor costs are assumed to increase with expected inflation and factor utilization. In particular, the growth rates of wages and the cost of capital are assumed to be set as follows:

$$
\begin{aligned}
& \Delta w_{t}=\pi_{t}^{*}+\lambda_{1} L U_{t} \\
& \Delta r_{t}=\pi_{t}^{*}+\lambda_{2} C U_{t},
\end{aligned}
$$

\footnotetext{
${ }^{4}$ For overviews of the NAIRU literature, see, e.g., Gordon (1997) and Staiger, Stock, and Watson (1997).

${ }^{5} \mathrm{We}$ assume that the inflation equation is homogeneous of degree one, so that a doubling in the growth rates of unit labor costs and in unit capital costs leads to a doubling in the inflation rate.
} 
where $\pi_{t}^{*}$ indicates expected inflation, $L U$ denotes labor utilization, and $C U$ denotes capacity utilization, with $\lambda_{1}, \lambda_{2} \geq 0$. This specification is similar to traditional expectations-augmented Phillips curve specifications in which factor costs (typically, wage costs) rise with the expected rate of inflation, and increase with output or decrease with unemployment. ${ }^{6}$ In our case, wages increase with expected inflation and labor utilization, while the cost of capital increases with expected inflation capacity utilization. ${ }^{7}$

Substituting (2) and (3) into (1) gives the following short-run Phillips curve:

$$
\pi_{t}=\pi_{t}^{*}-\alpha_{t}+\beta_{1} L U_{t}+\beta_{2} C U_{t}
$$

where

$$
\begin{aligned}
& \alpha_{t} \equiv \varphi \Delta a_{L, t}+(1-\varphi) \Delta a_{K, t} \\
& \beta_{1} \equiv \varphi \lambda_{1} \\
& \beta_{2} \equiv(1-\varphi) \lambda_{2} .
\end{aligned}
$$

To close the model, we assume that inflation expectations are formed adaptively:

$$
\pi_{t}^{*}=\sum_{i=1}^{\infty} \rho_{i} \pi_{t-i}
$$

with $\sum_{i=1}^{\infty} \rho_{i}=1$.

This implies the following short-run Phillips curve:

$$
\pi_{t}=\sum_{i=1}^{\infty} \rho_{i} \pi_{t-i}-\alpha_{t}+\beta_{1} L U_{t}+\beta_{2} C U_{t},
$$

or, equivalently,

$$
\Delta \pi_{t}=\sum_{i=1}^{\infty} \theta_{i} \Delta \pi_{t-i}-\alpha_{t}+\beta_{1} L U_{t}+\beta_{2} C U_{t},
$$

where

\footnotetext{
${ }^{6}$ For summaries of the expectations-augmented Phillips curve literature, which goes back to Friedman (1968), see Blanchard and Fischer (1989, chapter 10), or Romer (2001, section 5.4). While we treat utilization rates as exogenous here, it is also possible to make them endogenous, e.g., along the lines of Bils and Cho (1994) or Burnside and Eichenbaum (1996).

${ }^{7}$ A commonly accepted justification for the latter assumption is that the rate of capital depreciation depends on the rate of capacity utilization (e.g., Greenwood and others, 1988; and Burnside and Eichenbaum, 1996).
} 


$$
\theta_{i}=\sum_{j=1}^{i} \rho_{j}-1
$$

The nonaccelerating inflation rates of labor and capacity and utilization, NAILU and NAICU, are now defined as the utilization rates $L U^{*}$ and $C U^{*}$ for which there is no change in inflation, i.e., $\pi_{t}=\pi_{t-i}$ for all $i$ or $\Delta \pi_{t}=0$ for all $t$. For simplicity, we assume constant productivity growth $\left(\alpha_{t}=\alpha\right)$, so that the natural rates of factor utilization are constant over time. $^{8}$ This gives the following long-run Phillips curve:

$$
\alpha=\beta_{1} L U^{*}+\beta_{2} C U^{*} \text {. }
$$

This long-run Phillips curve is vertical (or more accurately, it is a vertical plane in threedimensional space with inflation on the vertical axis), implying that there does not exist a long-run trade-off between inflation and factor utilization. ${ }^{9}$

Substituting (10) into (8) gives

$$
\Delta \pi_{t}=\sum_{i=1}^{\infty} \theta_{i} \Delta \pi_{t-i}+\beta_{1}\left(L U_{t}-L U^{*}\right)+\beta_{2}\left(C U_{t}-C U^{*}\right),
$$

which gives the intuitive result that, for a given rate of capacity utilization, inflation accelerates when labor utilization is above its natural rate $\left(L U_{t}>L U^{*}\right)$; or vice versa, for a given rate of labor utilization, inflation accelerates when capacity utilization is above its natural rate $\left(C U_{t}>C U^{*}\right)$.

The quantitative analysis above can be summarized in a simple graph. The

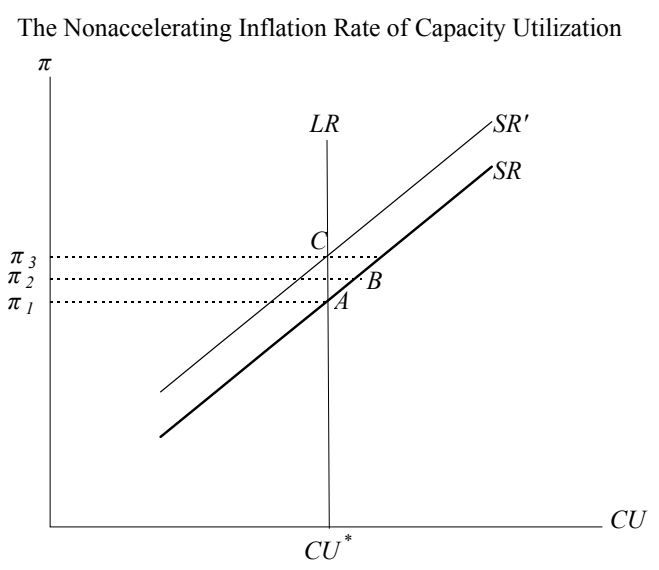
figure to the right plots inflation $(\pi)$ on the vertical axis against capacity utilization $(C U)$ on the horizontal axis. For simplicity, we assume here that labor utilization is fixed, but the analysis could easily be extended to the case of variable capacity and labor utilization. The curve denoted by $S R$ is the short-run Phillips curve, while the curve denoted by $L R$ is the long-run Phillips curve.

\footnotetext{
${ }^{8}$ Alternatively, we could allow the natural rates to increase with productivity growth.

${ }^{9}$ Note that, given the dependence of factor costs on inflation expectations, we would obtain the same vertical Phillips-curve under the extreme assumption of perfect foresight (inflation expectations are equal to actual inflation). However, in that case any inflation path, as long as it was predictable, would be consistent with equation (10).
} 
Suppose the economy is originally in equilibrium, that is, the capacity utilization rate $(C U)$ is at its "natural" level $C U^{*}$, corresponding to an inflation rate $\pi_{1}$. This is illustrated by point A in the graph. Assuming that production factors are fixed in the short run, a positive demand shock will then cause suppliers to increase their capacity utilization rate. This implies a shift from point $A$ to point $B$, that is, the increase in demand is met in part by an increase in capacity utilization, and in part by an increase in the inflation rate from $\pi_{1}$ to $\pi_{2}$. In the long run, however, there will not be a relation between capacity utilization and inflation because, if capacity utilization exceeds its natural rate and inflation increases, inflation expectations will also increase. As a result, workers will demand higher wages and lenders will demand higher interest rates, that is, factor costs increase. This causes the short-run Phillips curve to shift upward, from $S R$ to $S R$ ', so that, for a given rate of actual inflation, suppliers will now produce less. As a result, the economy moves from point $B$ to point $C$, that is, capacity utilization falls back to its natural rate, and inflation increases further, from $\pi_{2}$ to $\pi_{3}$. In this specification, therefore, any increase in demand that brings capacity utilization above its natural rate will only lead to inflation in the long run - which is why the long-run Phillips curve $(L R)$ is vertical.

\section{FACTOR UTILIZATION IN RUSSia}

In this section, we use the theoretical model presented above to estimate the natural rates of factor utilization in Russia, based on survey data. Survey estimates of factor utilization in Russia are provided by at least four different institutions: Rosstat (GKS), the Institute for the Economy in Transition (IET), the Russian Economic Barometer (REB), and the Center for Economic Analysis (CEA). ${ }^{10}$ All institutions provide indicators of capacity utilization, while the REB and the IET provide indicators of labor

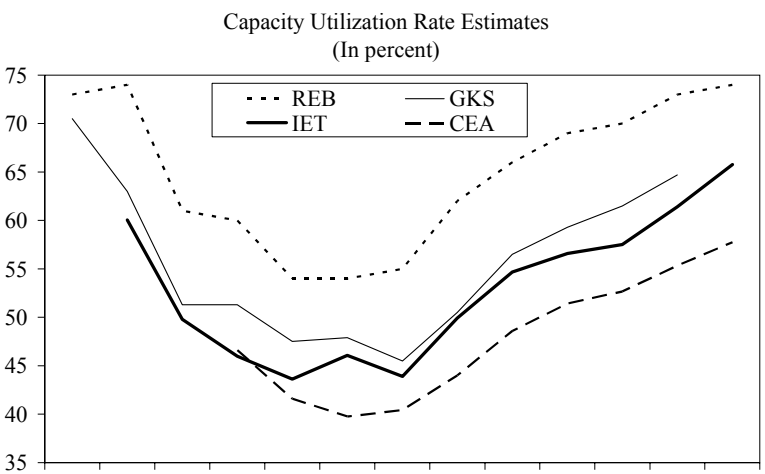

1992199319941995199619971998199920002001200220032004 utilization as well. The methodology and characteristics of the surveys are described in more detail in Appendix I. We restrict ourselves here to factor utilization in industry, as data on other sectors are fragmentary.

\footnotetext{
${ }^{10}$ In addition to these four institutions, Moscow Narodny Bank publishes an additional survey (conducted by NTC Research) that contains indirect estimates of capacity utilization, such as backlogs and supplier delivery times. We do not discuss these estimates here, as they are somewhat difficult to compare with the direct estimates of capacity utilization.
} 


\section{A. Capacity Utilization}

While the estimated capacity utilization rates vary widely, all available surveys suggest that capacity utilization in Russian industry has increased strongly since 1998. In particular, all surveys suggest a "U-shaped" pattern, with capacity utilization falling until 1996 or 1997 , and rising from 1998 or 1999 onward. However, the estimated rate of capacity utilization varies widely between the surveys, with the 2004 rate ranging between 58 percent (CEA survey) and 74 percent (REB survey). The reasons for these large differences are explained in Appendix I, and relate to differences in survey questions, sample design, and possible sample biases owing to differences in the size and age distributions of enterprises.

Consistent with the increase in capacity utilization, the share of enterprises with excess capacity has declined since 1998, while the share of enterprises with insufficient capacity has increased. This information is summarized by the "balance of capacity assessments," which is defined as the share of respondents who consider their capacity excessive, minus the share of respondents who consider their capacity insufficient. The balance increased slightly during 2001-02, possibly reflecting strong

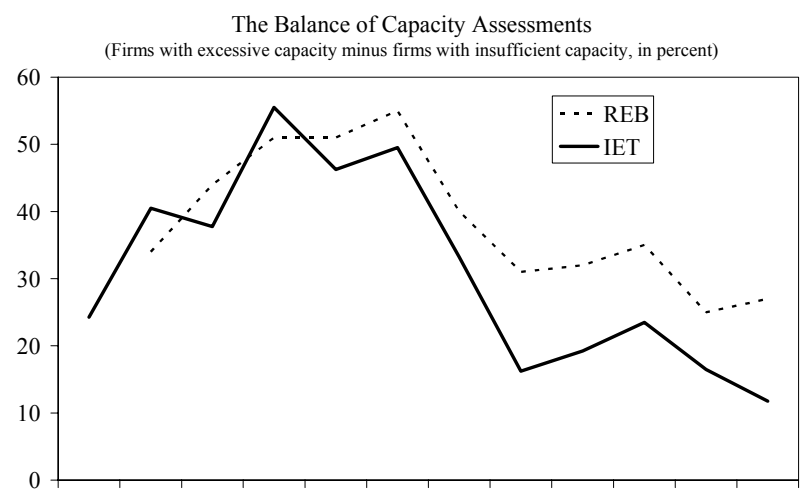

199319941995199619971998199920002001200220032004 investment growth during 1999-2001, combined with a slowdown in GDP growth in 2001. From 2002 onward, however, excess capacity declined again, although, according to the REB survey, it increased slightly in $2004 .^{11}$

In spite of their differences in levels, all capacity utilization estimates seem to be positively correlated with changes in inflation, as predicted by our model. This is illustrated with a simple graphical analysis that compares the evolution of capacity utilization with the monthly changes in the annual rate of core inflation for the past few years. ${ }^{12}$ The correlation between the change

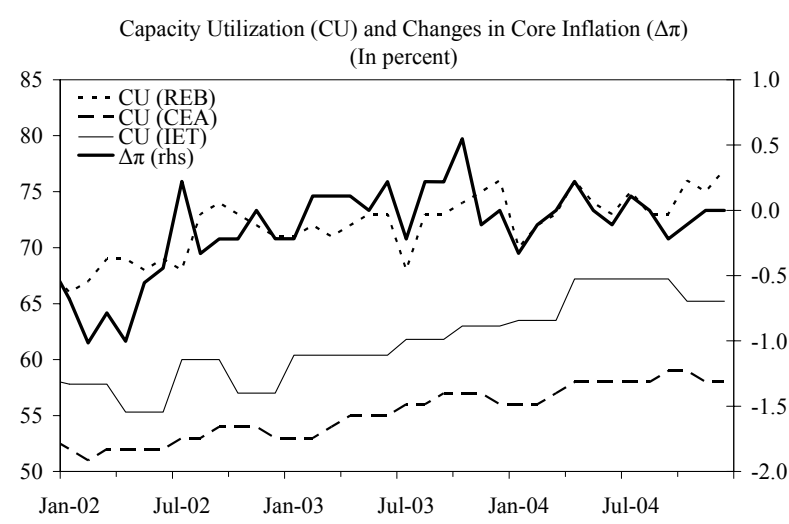

\footnotetext{
${ }^{11}$ Compared with the IET survey, the REB survey reports a larger share of respondents with "excess" capacity, an approximately equal share of respondents with "insufficient" capacity, and a smaller share of respondents with "sufficient" capacity.

${ }^{12}$ We use core inflation rather than headline inflation in order to eliminate the effects of seasonal food items and administered price adjustments, which are unrelated to underlying inflation. Following Nahuis (2003), we consider monthly changes in the annual (12-month) rate of core inflation in order to eliminate seasonal effects. Since the core CPI index is available only from January 1999, the monthly change in annual core inflation can
} 
in core inflation and the REB estimate of the capacity utilization rate is especially striking, but the other two estimates also appear to have a high correlation. We cannot assess the correlation with the GKS estimate, because the latter is available only at an annual frequency, while the annual change in core inflation can only be computed from 2000 , leaving us with far too few (4) data points to determine the correlation.

\section{B. Labor Utilization}

An overall estimate of labor utilization in Russian industry as a whole is provided by the REB survey. While the IET survey provides labor assessments by industry, we are reluctant to use this information for our analysis due to the low number of observations per industry. In addition, both the REB and the IET publish so-called labor assessments, in which enterprises are asked whether the amount of labor they have is insufficient, sufficient, or excessive given the expected demand. IET also publishes this information separately for each industry. While the REB and IET surveys do not clearly define the concept of labor utilization, it is likely interpreted by respondents as the ratio of actual hours worked to potential hours worked, given the number of employees.

The REB estimate of labor utilization suggests that Russia has witnessed a large increase in labor utilization since 1998, complementing the increase in capacity utilization. The estimated labor utilization rate increased from about 75 percent during 1994-98 to around 87 percent during 2000-04. A likely explanation for the initially low labor utilization rate is the existence of a

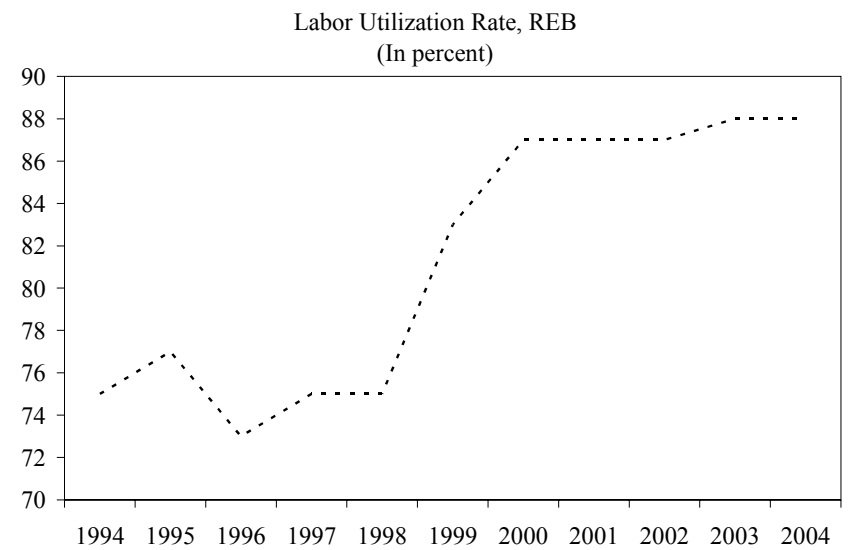
substantial amount of "hidden" or "disguised" unemployment—defined by Eatwell (1997) as employment in very low productivity occupations. Some of this disguised unemployment continued to exist during transition in the form of formally employed workers who were put on shortened working days or on compulsory leave (Dolinskaya, 2001, p. 11).

Virtually all of the increase in labor utilization occurred during 1999, when labor utilization increased from 75 percent to 85 percent. A possible explanation for this is the increase in demand for domestically produced goods resulting from the substantial real ruble depreciation that followed the August 1998 financial crisis, combined with higher oil prices. Apparently, manufacturing enterprises satisfied this increase in domestic demand by raising their historically low labor utilization rate, rather than by hiring new labor. 
Just as the balance of capacity assessments, the balance of labor assessments is defined as the share of respondents who consider their amount of labor excessive, minus the share of respondents who consider their labor insufficient, relative to expected demand. Starting in 2000, the balance has been close to zero for the IET survey and has even been negative for the REB survey. ${ }^{13}$ This suggests that the labor utilization rate since 2000 (around 87 percent) may have been close to its natural rate. $^{14}$

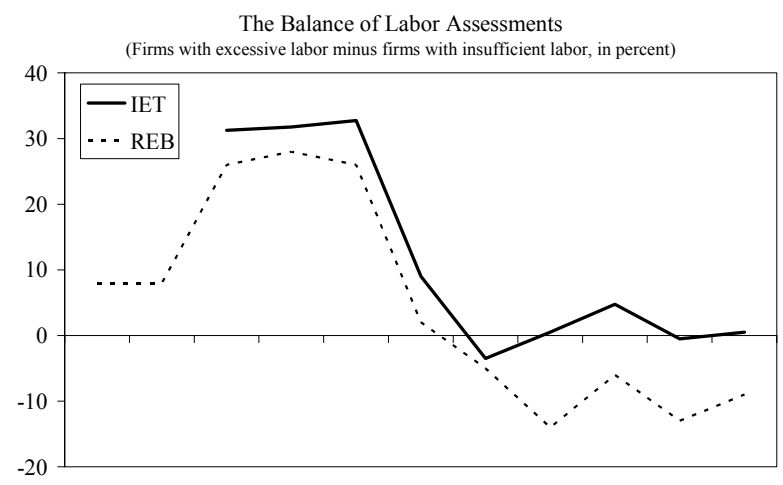

$\begin{array}{lllllllllll}1994 & 1995 & 1996 & 1997 & 1998 & 1999 & 2000 & 2001 & 2002 & 2003 & 2004\end{array}$

\section{Estimating the Natural Rate}

A simple way to estimate the NAICU is to plot the difference in core inflation against the capacity utilization rate, and see for which capacity utilization rate the change in core inflation is zero. This comes down to estimating equation (8) in the model presented above, while keeping labor utilization constant and ignoring lagged inflation.

The resulting scatter plot confirms that, for all capacity utilization measures (CEA, IET,

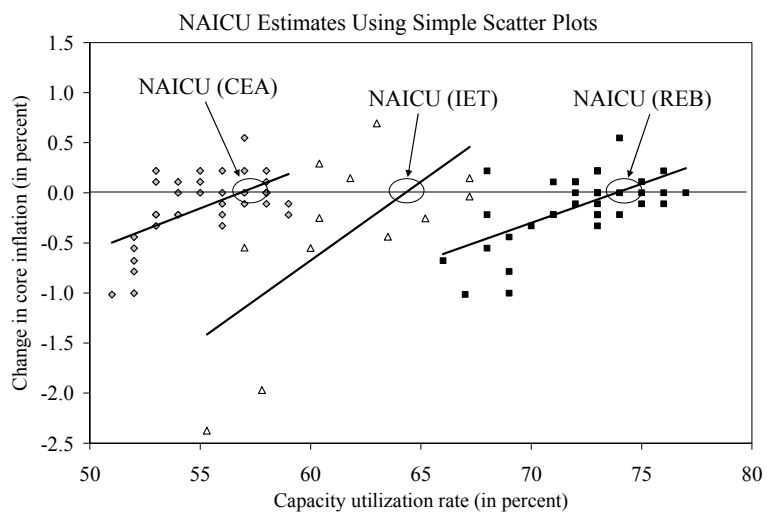

${ }^{13}$ It is somewhat surprising that the REB labor assessments are consistently below the IET labor assessments, while the REB capacity assessments are mostly above the IET capacity assessments. Since the REB survey seems biased toward smaller enterprises and the IET survey appears biased toward larger enterprises (see Appendix I), this suggests that smaller enterprises are more constrained in terms of labor, and less constrained in terms of capital, compared to larger enterprises. Another surprising fact is that the REB's labor assessment is very low in 1994-95, suggesting that there was not much spare labor in this period, which appears to be inconsistent with the low labor utilization rate reported by the REB for those years. A possible explanation for this is that the REB assesses available labor relative to expected demand during the next 12 months; hence, the reported lack of spare labor may simply reflect overly optimistic expectations regarding overall demand during the following 12 months.

${ }^{14}$ While there is no one-to-one relationship between the NAILU and the NAIRU, it is interesting to note that another study (Bragin and Osakovsky, 2004) estimates that, from 2000 to 2003, the unemployment rate in Russia was also approximately equal to its natural rate. This finding is not based on the labor utilization estimates discussed above, but on an error-correction-type model in which changes in employment are a function of changes in output, changes in inflation, and the difference between actual and natural employment, where the latter is an unobserved variable. 
and REB), there is, indeed, a positive correlation between the change in core inflation and the capacity utilization rate. Not surprisingly, the NAICU estimates are different for each survey, for the same reasons why their capacity utilization estimates are different. Thus, the CEA survey data generate the lowest NAICU estimate (around 56 percent), and the REB survey data generate the highest NAICU estimate (around 74 percent), while the IET survey data generate a NAICU estimate that is somewhere in between (around 65 percent).

It is not surprising that the NAICU estimates for Russia are somewhat lower than those for advanced economies. For the United States, the NAICU has been consistently estimated at around 82 percent, ${ }^{15}$ and for Western European economies at 75 to 85 percent. ${ }^{16}$ Generally, the NAICU is expected to be higher in countries with more competition, better management techniques, and more flexible product and labor markets (Nahuis, 2003). It is natural, therefore, to observe lower NAICUs for transition economies like Russia. Even for a highly developed market economy, however, the NAICU is still likely to be below 100 percent. ${ }^{17}$

More formal econometric tests suggest that the NAICU estimates based on scatter plots are robust to the inclusion of lagged changes in inflation and other variables. Unit root tests and economic intuition suggest that all variables are stationary, ${ }^{18}$ so that we can estimate equation (8) by OLS. However, we are not able to impose condition (9) and solve for $C U^{*}$ and $L U^{*}$ in equation (10). This is because equation (10) has three known variables $\left(\Delta \pi_{t}, C U_{t}\right.$, and $\left.L U_{t}\right)$ and four unknown parameters $\left(\beta_{1}, \beta_{2}, C U^{*}\right.$, and $\left.L U^{*}\right)$ which, therefore, are not identified.

Nevertheless, we are able to estimate $\beta_{1}$ and $\beta_{2}$ in equation (8), the results of which suggest that $\beta_{1}$ is not significantly different from zero, that is, there is no significant impact of labor

\footnotetext{
${ }^{15}$ The NAICU estimate of 82 percent for the United States is surprisingly robust (e.g., McElhattan, 1985; Garner, 1994; Corrado and Mattey, 1997; and Emery and Chang, 1997) and is generally used as an indicator of inflationary pressure, by U.S. Federal Reserve banks and private investors alike.

${ }^{16}$ Franz and Gordon (1993) estimate the NAICU for Germany at 84.7 percent. Nahuis (2003) finds NAICUs at around 84 percent for France, Germany, the Netherlands, and the United Kingdom; around 78 percent for Belgium, Greece, and Ireland (with no significant effects for Greece and Ireland); and around 75 percent for Italy. We are not aware of any NAICU estimates for transition or developing economies.

${ }^{17}$ Burnside and Eichenbaum (1996) present a model in which it is optimal for firms to set their capacity utilization rate below 100 percent, because this allows them to immediately increase the effective stock of capital in response to shocks that raise the marginal product of capital.

${ }^{18}$ Oomes and Ohnsorge (2005) conduct unit root tests for a similar inflation model for Russia, and find that the changes in Russian headline inflation, unit labor costs, and the nominal effective exchange rate are stationary for the period 1996-2004. We do not have sufficient observations to run the same unit root tests for core inflation, because data for the core CPI index are available only from January 1999; hence, the monthly change in annual core inflation can be computed only from February 2000. Economic intuition suggests that $C U$ and $L U$ are stationary because they are bounded.
} 
utilization on the change in inflation. ${ }^{19}$ The most likely explanation for this finding is that, as shown above, the labor utilization rate for Russia was roughly constant from 2000 onward (at around 87 percent), as a result of which there is insufficient variation in the data to explain the variation in inflation during this period. ${ }^{20}$ Nevertheless, we could assume for simplicity that labor utilization was at its natural rate between 2000 and 2004.

Setting $\beta_{1}=0$ or $L U_{t}=L U^{*}$ (and defining $\beta=\beta_{2}$ ) allows us to identify the NAICU by estimating the equation

$$
\Delta \pi_{t}=\sum_{i=1}^{\infty} \theta_{i} \Delta \pi_{t-i}+\beta\left(C U_{t}-C U^{*}\right)+\varepsilon_{t}
$$

while imposing the restriction

$$
C U^{*}=\frac{\alpha}{\beta}
$$

which is equivalent to running the regression

$$
\Delta \pi_{t}=\sum_{i=1}^{\infty} \theta_{i} \Delta \pi_{t-i}-\alpha+\beta C U_{t}+\varepsilon_{t}
$$

Tables B1 through B3 in Appendix II report the regression results for equation (11), using the REB, IET, and CEA estimates of capacity utilization, respectively. The first column of each table reports the results for the regression where $\theta_{i}=0$ for all $i$, which corresponds to the estimates based on trend lines for simple scatter plots. These results suggest that capacity utilization has a significant effect on inflation, with the NAICU estimated at around 75 percent for the REB estimate of capacity utilization, 57 percent for the CEA estimate, and 66 percent for the IET estimate. ${ }^{21}$ However, as the residual tests show, these regressions are generally not valid because the residuals are not well behaved: they do not have a normal

\footnotetext{
${ }^{19}$ These results are available from the authors upon request.

${ }^{20}$ Another problem that could potentially complicate the estimation of $\beta_{1}$ and $\beta_{2}$ is potential multicollinearity between capacity and labor utilization, which may lead to biased estimates. A similar point is made by McElhattan (1978, p. 23) concerning the multicollinearity between the NAICU and the NAIRU for the United States. However, multicollinearity was not a problem in our case because of the relative constancy of $L U$ during the sample period.

${ }^{21}$ These estimates are slightly different from those presented in the scatter plots because of the longer sample period. To obtain comparable results and lengthen the sample period for the IET data, we interpolated the quarterly IET estimates by assuming identical capacity utilization rates for the three months within each quarter.
} 
distribution and are significantly autocorrelated (i.e., the null hypotheses of no normality and no autocorrelation are rejected).

The second and third groups of columns in Tables B1 through B3 show that allowing for lags and other inflation determinants improves the validity and fit of the regressions, but does not significantly change the NAICU estimates. In addition to allowing for lags (non-zero $\theta_{i}$ 's), we also control for other possible inflation determinants, including the growth in broad money (M2 plus foreign currency deposits), the nominal effective exchange rate (as a proxy for import prices), and the Urals oil price. The number of lags were chosen in order to minimize the information criteria, using a general-to-specific estimation methodology. The results, reported in the third column of each table, show that the equations are well-behaved, the effect of capacity utilization on inflation is still significant, and the NAICU estimates are very similar even after controlling for all other variables.

All estimates suggest that the capacity utilization rate was above its natural rate at end-2004, although this difference is not significant for the IET and the CEA survey data. ${ }^{22}$ As Table 1 shows, the end-2004 capacity utilization rate is above the estimated 95 percent confidence interval for the NAICU (point estimate $\pm 1.96 *$ standard error) when using the REB measure of capacity utilization but falls within the confidence interval when using the IET and CEA estimates.

Table 1. Estimated Natural and Actual Capacity Utilization Rates (In percent)

NAICU (point estimate) NAICU (95 percent confidence interval) $\quad C U$ at end-2004

\begin{tabular}{lccc}
\hline REB & 74.3 & $72.5-76.0$ & 77.0 \\
IET & 65.6 & $63.5-67.6$ & 65.2 \\
CEA & 57.2 & $56.2-58.3$ & 58.0
\end{tabular}

\footnotetext{
${ }^{22}$ The REB capacity utilization estimate for end-2005 was 79. IET and CEA estimates for end-2005 were not yet available at the time of writing.
} 


\section{Output Gap Estimates}

The output gap, which measures the extent to which GDP is above or below its potential, is the most general indicator of the cyclical position of an economy. It is a more general indicator than either capacity utilization or labor utilization, since it takes into account bothbecause output is a function of both capital and labor. If output is above potential, supplyside constraints imply that producers cannot easily meet an increase in demand with an increase in supply; hence, inflationary pressures will build up. If output is below potential, an increase in demand can easily be met with an increase in supply, and therefore will not result in inflationary pressures.

There are three main methods for estimating the output gap. ${ }^{23}$ The first and simplest method is arithmetic trend fitting, which comes down to the assumption that potential output follows a linear, quadratic, or exponential trend. The second method is the use of univariate statistical filters, in particular, the Hodrick-Prescott (HP) filter and the Christiano-Fitzgerald (CF) filter. Finally, the third method we use is the so-called production function approach, which involves estimating a production function for the Russian economy, and which incorporates the capacity and labor utilization estimates discussed above. The technical details behind the first two approaches are described in Appendix III, and the third approach is described in detail in the text. ${ }^{24}$

All methods have advantages and disadvantages. The first method, arithmetic trend fitting, has the advantage of being simple, but its disadvantages are that it is a purely statistical method, and that it tends to generate unrealistic swings in the output gap if the actual trend is different from its assumed shape (e.g., linear, quadratic, or exponential). The second method, univariate statistical filtering, has the advantage of producing smoother estimates of the output gap (in particular, the CF filter); however, it is also a purely statistical method without any economic foundations. In addition, it has the disadvantage of being subject to so-called end-of-sample bias (see Appendix III). The advantages of the third method, the production function approach, are that it is based on economic theory, allows us to use and combine our capacity and labor utilization estimates, and does not necessarily assume that output gaps are zero on average. The disadvantage of this approach, however, is that it is based on several assumptions that may be unrealistic for Russia (e.g., profit maximization, perfect competition, and constant returns to scale), and requires us to estimate several parameters

\footnotetext{
${ }^{23}$ A fourth popular method for estimating the output gap, which we do not discuss here, is to identify structural demand and supply shocks in a vector autoregression (VAR), using a Blanchard-Quah type variance decomposition approach. We believe this method is difficult to apply to Russia, given the short time series available, the existence of structural breaks, and the difficulty involved in disentangling demand shocks from supply shocks, given that oil prices are correlated with both.

${ }^{24}$ For a useful discussion and comparison of these output gap estimation methods, see Billmeier (2004a and 2004b).
} 
that are imprecisely measured (the capital stock, capital and labor shares, capital and labor utilization, and the NAICU and NAILU).

We use all three methods to estimate the output gap in Russia for the period 1999-2004. While earlier data are available, we decided not to use these, as all output gap estimation methods implicitly assume that the structure of the economy remains constant over time. Clearly, this was not the case in the early transition years, and certainly not in the crisis year 1998. While one could argue that the structure of the Russian economy has continued to change even since 1998, we believe that it has been sufficiently stable to allow estimation of the output gap. For the statistical approaches (the first two methods), we use seasonally adjusted quarterly GDP data. However, since quarterly data are not available for the capital stock, we use annual data for the production function approach.

\section{A. Trend Fitting and Statistical Filtering}

When potential output is estimated using arithmetic trends, the results suggest that the output gap was positive during 2000-01:H1, and possibly again during 2004. As Figure 1 shows, the results do not depend much on the assumed trend for GDP: linear, quadratic, and exponential trends all give a similar pattern. All estimates suggest that output was above potential from 2000 through mid-2001, then fell below potential as GDP growth slowed, and started exceeding potential again around 2003:Q4.

When potential output is estimated using statistical filters, the results are very similar. We first de-trend the seasonally adjusted GDP data by using several different HP filters, each of which smooth the output series to a different extent (see Appendix III for details). The resulting trend is typically interpreted as potential output. Since the HP filter is sensitive to the "end point problem," it is necessary to extend the actual GDP series with projections for 2005. As the bottom panel of Figure 1 illustrates, smoothing the GDP data by using a CF filter, which uses a different methodology than the HP filter (see Appendix III), results in a significantly smoother estimate of the output gap. Judged from these estimates, there is less evidence that output was above potential in 2004. However, the de-trended version of the CF filter, which is probably the most appropriate one, does result in a slightly positive output gap in the last quarter of 2004.

\section{B. Production Function Approach}

The traditional trend-fitting and statistical-filtering approaches to output gap estimation may not be appropriate for a transition economy like Russia, since they implicitly assume that the output gap is zero on average. Both types of approaches decompose actual growth in trend and cyclical components and, therefore, implicitly assume that "average" growth corresponds to potential growth. This is most obvious in the case of a linear trend, which is estimated by minimizing squared deviations. By construction, this implies that deviations from the trend are zero on average, that is, there must be periods with both positive and negative output gaps. While this assumption seems reasonable over long periods of time for relatively stable 
economies, it does not seem appropriate for transition economies like Russia, which have experienced large structural changes over short periods of time. ${ }^{25}$

Most problems inherent in trend fitting and filtering can be avoided by using a production function approach. Most important, this approach does not assume that output gaps are zero on average for a given sample. This is because, under the production function approach, potential output is defined as the level of output that is produced when both capacity and labor utilization (and total factor productivity) are at their natural rates. Thus, whether or not the output gap will be zero on average depends on whether the factors of production are, on average, at their natural rates. Another advantage of the production function approach is that it does not necessarily assume that the structure of the economy is stable over time; for example, it is possible to have time-varying labor and capital shares (although for Russia, these shares have been rather stable, as shown below). ${ }^{26}$

The production function approach assumes that firms maximize profits and that production is constant returns to scale. We estimate a standard Cobb-Douglas production function of the form $Y=A L^{\alpha} K^{\beta}$, where $Y$ denotes real output, $A$ denotes total factor productivity (TFP), $L$ is total employment, $K$ is the capital stock, $\alpha$ denotes the labor elasticity of output, and $\beta$ denotes the capital elasticity of output. Under the assumption of profit maximization, the labor elasticity equals the labor share of income, and the capital elasticity equals the capital share of income. ${ }^{27}$ Under the assumption that production is constant returns to scale $(\alpha+\beta=1)$, the labor share and the capital share of income sum to one.

\footnotetext{
${ }^{25}$ In fact, the evolution of real GDP in almost all transition economies displays a "V"-shape, with negative real GDP growth rates through the mid-1990s (for Central and Eastern European economies) or even until the end1990s (for most CIS countries), and positive growth rates after that. If one were to estimate the output gap for the entire 1990s using trending methods, the output gap would by construction be positive both at the beginning of the sample and at the end of the sample.

${ }^{26}$ Moreover, we assume that the NAICU and the NAILU have been constant over time. While it would be interesting to test this assumption, we currently do not have a sufficient number of observations to do this.

${ }^{27}$ To see this, consider the profit maximization problem $\max \Pi=P Y-W L-R K$, s.t. $Y=A L^{\alpha} K^{\beta}$, where $P$ is the GDP deflator (i.e., $P Y=$ nominal GDP), $W$ is the average nominal wage, and $R$ is the average cost of renting capital. It is straightforward to show that the first-order conditions to this problem are $\alpha=W L / P Y$ and $\beta=R K / P Y$.
} 


\section{Figure 1. Output Gap Estimates Using Arithmetic Trends and Statistical Filters}
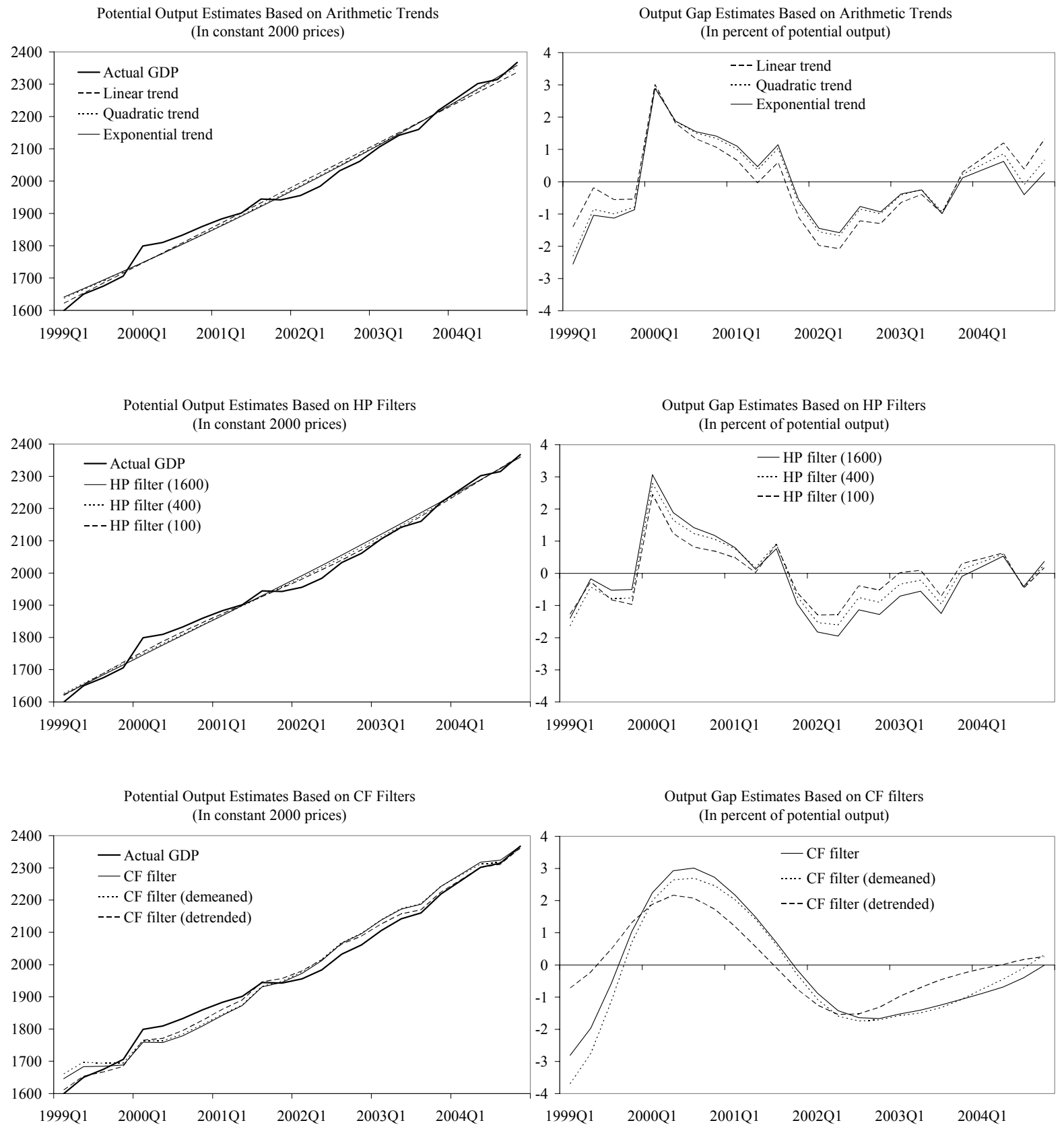
Capital and labor shares in Russia are estimated to have been roughly equal. Using national accounts data on GDP by income source, labor income can be estimated as the category "average earnings of employees" (which includes income taxes, social insurance payments, and so-called "hidden wages") and capital income as the category "gross profits and gross mixed income." 28 Using these estimates, we find that, during the period 1995-2004, the labor share was roughly 50 percent. The labor share slightly

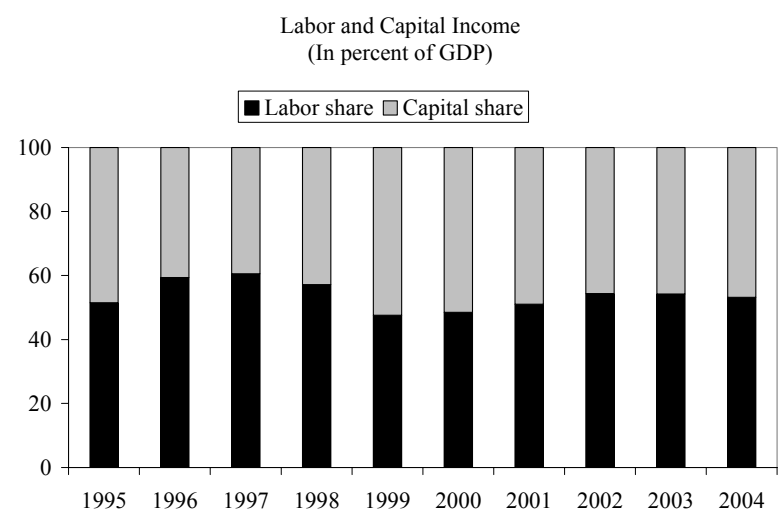
decreased during 1999 and 2000, suggesting that wages, rather than profits, took the biggest hit following the 1998 financial crisis.

We estimate labor and capital inputs by adjusting official data on the capital stock and employment for capacity and labor utilization. That is, we estimate a production function of the form

$$
Y=A\left(u_{L} L\right)^{\alpha}\left(u_{K} K\right)^{1-\alpha}
$$

where $u_{L}$ denotes labor utilization and $u_{K}$ denotes capital utilization. We take the capacity utilization measures estimated for industry as proxies for the economy wide $u_{K}$ and calculate the output gap separately for each measure. Since we have only one (REB) measure of $u_{L}$, we use this measure in all our estimates of the output gap. As argued above, our estimates of $u_{L}$ and $u_{K}$ suggest that one would overestimate actual capital and labor input by using official statistics on employment and the capital stock. Nevertheless, researchers who use the production function approach to estimate the output gap typically do not adjust for utilization. Moreover, they generally assume that capital is always at its potential — which, as we have seen, is a bad assumption, at least for Russia.

Without adjusting for utilization, the contribution of total factor productivity (TFP) growth to GDP growth is seriously overestimated. ${ }^{29}$ This is illustrated in the figures below, which show

\footnotetext{
${ }^{28}$ The category "gross profits and gross mixed incomes" is equal to that part of the value-added component that remains with producers after deducting expenditures related to the compensation of employees and net taxes on production and imports. Since net taxes on production and imports do not accrue to either capital or labor, we exclude them from the definition of total income, so as to ensure that the labor share and capital share sum to one.

${ }^{29}$ Similar observations for Russia have been made by Dolinskaya (2001), Bessonov (2004), and Lissovolik (2004). The same observation applies to U.S. data as well. A number of papers have found that, when variable capital and labor utilization rates are introduced into real business cycle models, the assumed volatility in TFP needed to explain the observed variability in U.S. output is significantly reduced: by 20 percent in Bils and Cho (1994); by 33 percent in Burnside and Eichenbaum (1996); and by 20-40 percent in Baxter and Farr (2005).
} 
the decomposition of GDP growth into capital, labor, and TFP growth, using the REB estimates of capacity utilization and labor utilization. The first figure shows that, without adjusting for utilization, the contribution of capital and labor to total GDP growth is almost negligible. This is natural, given that, according to official Rosstat data, the capital stock grew by only 0.1 to 1 percent per year throughout $1999-2004,{ }^{30}$ while employment grew by -1.5 to 2.5 percent per year. The second figure shows that, when we adjust for capacity utilization, the contributions of capital and labor are much larger. In fact, the increase in capacity utilization appears to have been an important factor behind GDP growth in all years since 1998, while the increase in labor utilization was an important factor in the years 1999 and 2000.
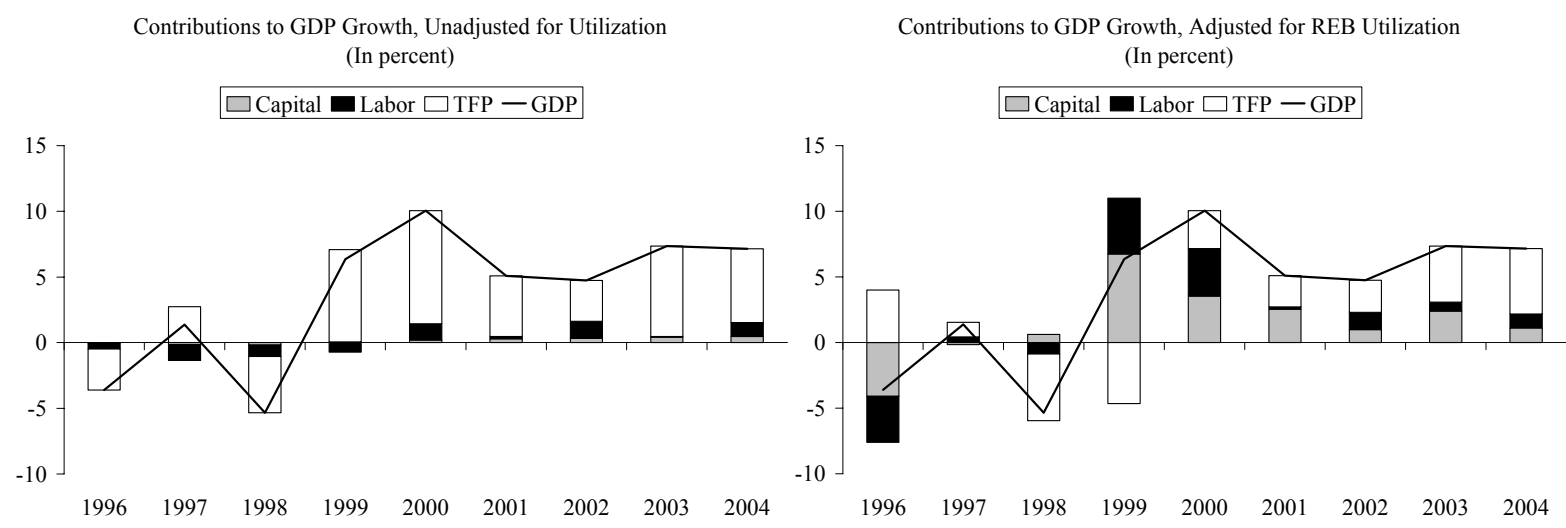

We estimate potential output by evaluating the estimated Cobb-Douglas production function at potential employment, potential capital, and potential TFP. That is, we estimate the following production function:

$$
Y=A^{*}\left(u_{L}^{*} L\right)^{\alpha}\left(u_{K}^{*} K\right)^{1-\alpha},
$$

where $A^{*}$ denotes potential TFP, $u_{L}^{*}$ is the NAILU, and $u_{K}^{*}$ is the NAICU. Thus, potential employment and the potential capital stock are estimated by assuming that they are at their natural rates. We assume the natural rate of labor utilization to be 87 percent, as the data on labor assessments suggest, and we set the $u_{K}^{*}$ equal to our various estimates of the NAICU. For each capacity utilization survey, we also compute a lower and upper bound for potential output, based on the estimated 95 percent confidence interval for the NAICU.

Using the REB survey data, we estimate the growth rate of potential TFP at around 4 percent. Potential TFP $\left(A^{*}\right)$ is estimated using exponential trend fitting, which implicitly assumes that the growth rate of potential TFP has been constant during the period 1999-2004. The

\footnotetext{
${ }^{30}$ Because 2004 data were not yet available during the time of this exercise, the estimate for 2004 is obtained by extrapolation.
} 
estimated exponential trend suggests that TFP has grown on average by 4.1 percent a year between 1999 and $2004 .^{31}$ The assumption of a constant growth rate turns out to be a reasonable assumption, as the deviations between actual and potential TFP are quite small.

All production function estimates suggest that output was below potential until recently, with the output gap narrowing from between -10 and -20 percent in 1999

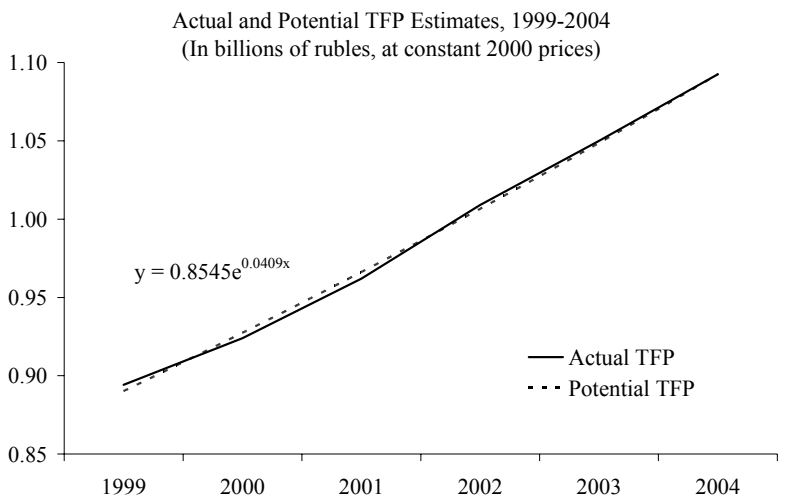
to around zero percent in 2003-04. The finding of an initially negative output gap is natural given that, until recently, capacity utilization was below its natural rate, while labor utilization and TFP were near their potential. Similarly, the finding that the output gap has narrowed over time follows from our earlier finding that capacity utilization has approached its natural rate. Note that a negative output gap does not mean that GDP growth has been below potential. On the contrary, as Figure 2 shows, a negative but narrowing output gap implies that, even though the level of actual GDP remained below potential, the growth of actual GDP consistently exceeded potential GDP growth.

The production function estimates also suggest that the output gap may have become positive in 2005. Based on the REB and CEA survey data, we find that the output gap was significantly positive in 2005, although it is not significantly different from zero when using the IET data. However, we should note that the output gap estimate for 2005 depends only on the actual growth rate and an assumed potential growth rate, because all necessary data for 2005 were not yet available at the time of writing. We assumed potential growth in 2005 to equal 5 percent, which is the estimated potential growth rate for 2004 averaged over the three surveys. ${ }^{32}$ Given that actual GDP growth in 2005 was 6.4 percent, this assumption naturally implies that the output gap increased slightly in 2005. If we had assumed a higher potential growth rate, the estimated output gap would have increased by less and may not have been found to be significantly positive. ${ }^{33}$

\footnotetext{
${ }^{31}$ This estimate is close to Lissovolik's (2004) TFP growth estimate of 3.7 percent during 1999-2002.

${ }^{32}$ The assumption of 5 percent is also consistent with the Russian government's draft medium-term socioeconomic development program for 2005-08, in which it was argued that the Russian economy would not be able to arrive at sustainable rates of GDP growth higher than 4 to 5 percent per year.

${ }^{33}$ At the time this WP was about to be published, REB estimates through end-2005 just became available, and they indicated that average capacity utilization increased from 74 percent in 2004 to 76 percent in 2005. Preliminary regression estimates for the extended sample through end-2005 also suggest a higher NAICU estimate (of almost 78 percent), implying that the output gap may still not have been significantly different from zero in 2005. These estimates, which are based on a slightly modified regression, are available upon request from Hajime Takizawa (htakizawa@imf.org).
} 


\section{Figure 2. Output Gap Estimates Based on the Production Function Approach}
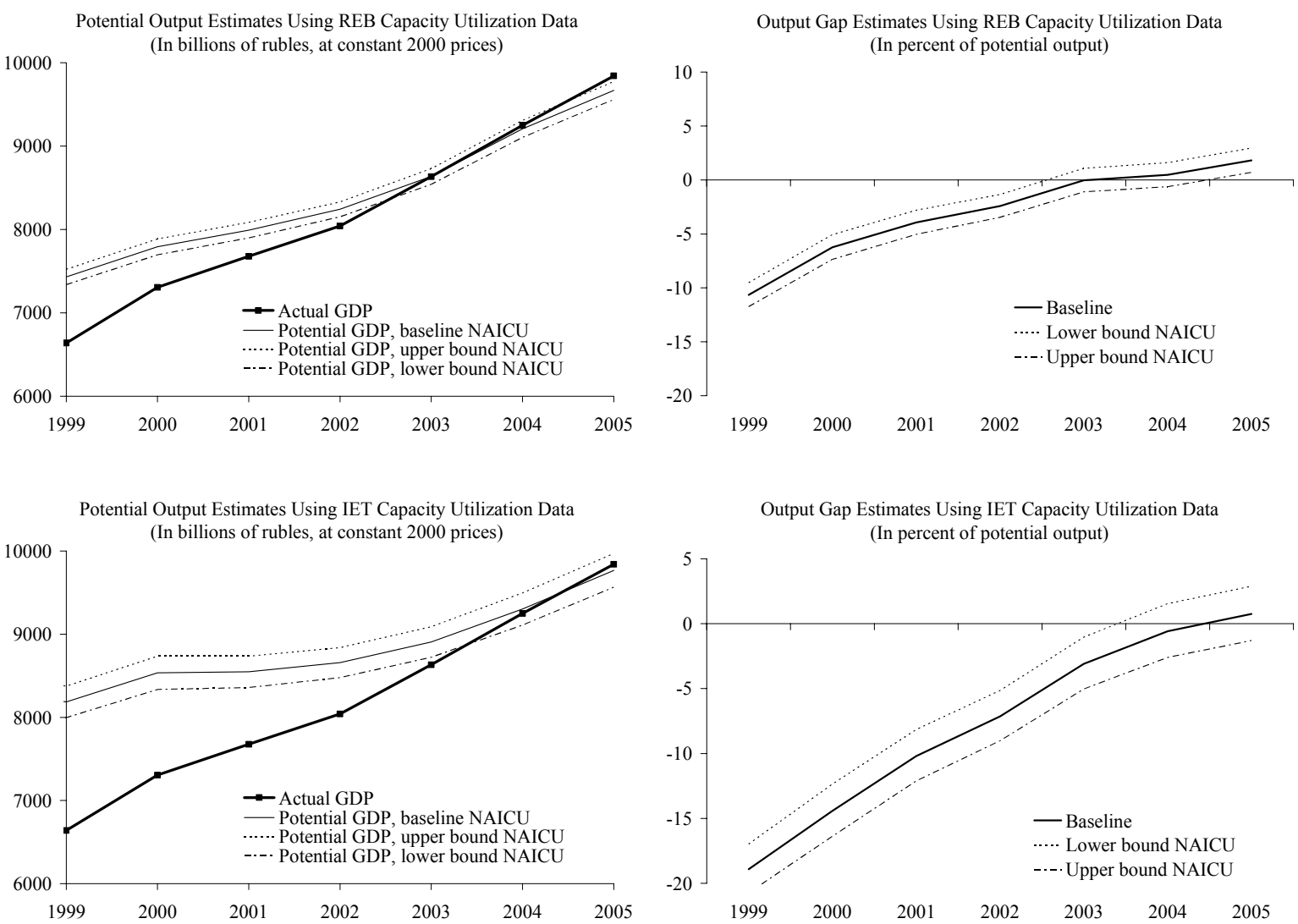

Potential Output Estimates Using CEA Capacity Utilization Data
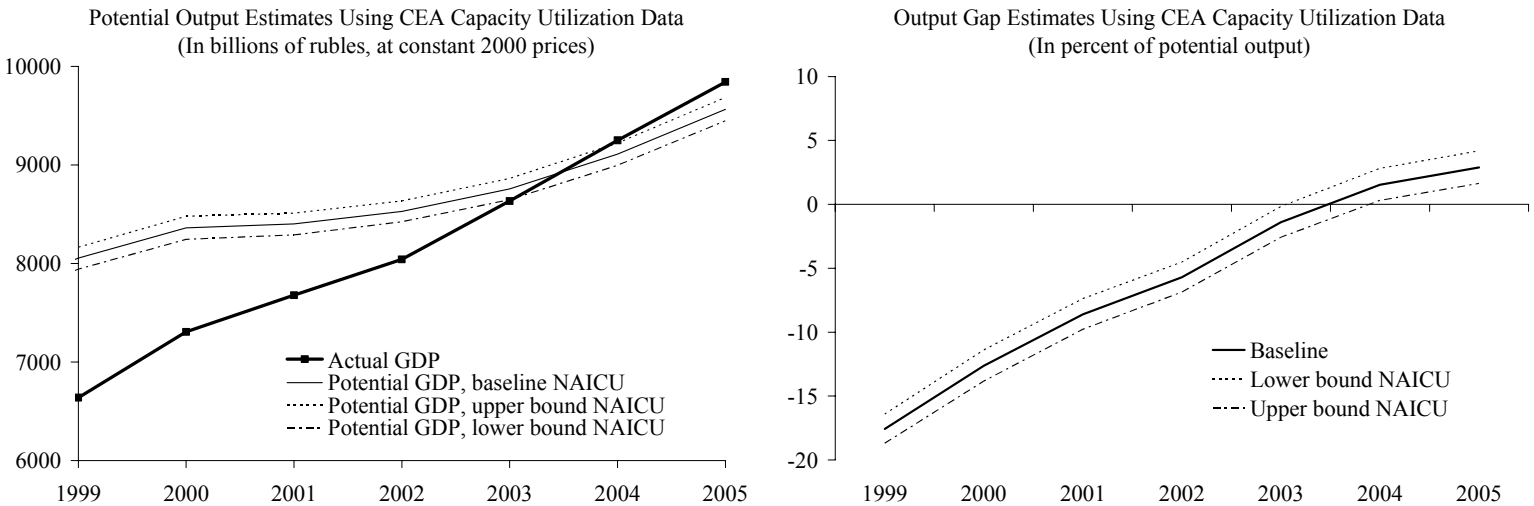


\section{Conclusions}

In this paper, we have tried to answer the question of whether the entrenchment of core inflation in Russia can be explained by the existence of supply-side constraints. We have done so by estimating the nonaccelerating inflation rate of capacity utilization (NAICU) and the nonaccelerating inflation rate of labor utilization (NAILU), and by employing several approaches for estimating the output gap.

While estimates of the Russian NAICU vary across surveys, all surveys agree that capacity utilization has increased substantially since 1999 and may currently be above its natural rate, thus contributing to inflationary pressures. The NAICU estimates differ across surveys because of different survey definitions and different degrees of sample bias in terms of firm size and age distributions (see Appendix I). However, we show econometrically that each capacity utilization measure has a significant effect on inflation, and that our NAICU estimates are robust to controlling for inflation persistence and other inflation determinants. While we were not able to obtain significant regression estimates for the NAILU, available survey data suggest that labor utilization has been around its natural rate since 2000 - a situation that may have contributed to inflationary pressures as well.

Statistical methods for estimating the output gap suggest that it was positive during 2000-01, which seems inconsistent with utilization data. This finding appears to be a statistical artifact, however, in that trend fitting and filtering methods assume, by construction, that the output gap is zero on average, even in a short sample.

A production function approach, which takes into account the capacity and labor utilization estimates, suggests that the output gap has been negative until recently. This approach incorporates utilization-adjusted capital and labor inputs, and estimates potential output at the NAICU and the NAILU. The results suggest that the output gap was negative but gradually declining between 1999 and 2003, and closed in 2003 or 2004.

All output gap methods suggest that Russia's output gap has been gradually closing since 2002, and is currently near zero. If these estimates are correct, they imply that faster-thanpotential growth can now be achieved only at the cost of higher inflation. 


\section{Characteristics and Methodology of Capacity Utilization Surveys}

This Appendix describes the main characteristics and methodologies behind the four capacity utilization surveys discussed in the paper, with a focus on assessing their representativeness. The four surveys discussed are those by Rosstat (Section A), the Institute for the Economy in Transition (Section B), the Russian Economic Barometer (Section C), and the Center for Economic Analysis (Section D). The main characteristics of the surveys are summarized in Tables A1 and A2 below.

Table A1. Capacity Utilization Survey Characteristics

\begin{tabular}{lllll}
\hline & GKS & IET & REB & CEA \\
\hline Indicators & $\begin{array}{l}\text { Capacity } \\
\text { utilization }\end{array}$ & $\begin{array}{l}\text { Capacity and } \\
\text { labor utilization }\end{array}$ & $\begin{array}{l}\text { Capacity and } \\
\text { labor utilization }\end{array}$ & $\begin{array}{l}\text { Capacity } \\
\text { utilization }\end{array}$ \\
\hline $\begin{array}{l}\text { Sample size } \\
\text { (number of firms) }\end{array}$ & 7,000 & 1,200 & 500 & 1,400 \\
\hline $\begin{array}{l}\text { Response rate } \\
\text { (in percent) }\end{array}$ & $\ldots$ & $65-70$ & $30-40$ & 85 \\
\hline Weighting & Yes & Yes & No & No \\
\hline Frequency & Annual & Quarterly & Monthly & Monthly \\
\hline First observation & 1992 & Q1 1993 & Dec 1991 & May 1995 \\
\hline
\end{tabular}

Table A2. Population and sample size distribution of Russian industrial enterprises, 2003 1/ (In percent)

\begin{tabular}{llrrrr}
\hline & & Population 2/ & IET & REB & CEA 3/ \\
\hline Small & $(<500$ employees $)$ & 38 & 9 & 58 & 33 \\
Medium & $(500-1,000$ employees $)$ & 18 & 17 & 20 & 23 \\
Large & $(>1,000$ employees $)$ & 44 & 74 & 22 & 44 \\
Total & 100 & 100 & 100 & 100 \\
\hline
\end{tabular}

1/ For the population and the IET, the shares in terms of number of enterprises are weighted by the average number of employees.

2/ Total set of registered industrial enterprises used by Rosstat for calculating official industry statistics (e.g., industrial production, producer price index).

3/ CEA data are based on the December 2004 distribution.

One main reason for the systematic differences in capacity utilization estimates is that the four surveys ask slightly different questions. Perhaps most important, Rosstat defines "capacity utilization" as the ratio of actual output to the maximum possible output, given a normal operating cycle, ${ }^{34}$ while the REB defines the capacity utilization rate as the level of

\footnotetext{
34 This is similar to the U.S. Federal Reserve Board's definition of potential capacity as "sustainable maximum output," that is, "the greatest level of output a plant can maintain within the framework of a realistic work schedule after factoring in normal downtime and assuming sufficient availability of labor and material inputs to operate the capital in place" (Morin and Stevens, 2004a, p. 3; see also Morin and Stevens, 2004b). Morin and Stevens (2004a) argue that it is important that potential capacity be defined as a "sustainable maximum" rather
} 
used capacity in percent of the normal monthly level. ${ }^{35}$ Since the "normal" level is likely to be less than the "maximum" level, this likely explains why the REB capacity utilization rate estimates are the highest. ${ }^{36}$ Another, related reason why REB estimates are the highest, and those of CEA the lowest, is that the maximum capacity utilization rate that respondents can report is "higher than 120 percent" in the REB survey, and "91-100 percent" in the CEA survey. Until July 2001, the IET used to have "higher than 90 percent" as its highest possible capacity utilization rate, but since that time it is no longer restricting the possible answers respondents can give. Rosstat also does not seem to give any restrictions. Finally, the differences between the REB and IET balance of capacity assessments can in part be explained by the fact that the REB asks its respondents to assess capacity relative to expected demand during the next 12 months, while the IET refers to "expected demand" over an unspecified period, which is likely interpreted as the near future.

A second reason for the systematic differences in capacity utilization estimates across the four surveys is that they have different degrees of sample bias in terms of size distribution. To obtain a representative (unbiased) estimate of average capacity utilization, one needs to either (1) take a random sample and weight responses by capacity shares (proxied by output or employment shares); or (2) construct a sample with a capacity distribution similar to that of the population, and not weight responses. As argued below, most surveys (except the CEA) do not satisfy either one of these two conditions, as a result of which most samples appear to suffer from selection bias. ${ }^{37}$

A third reason why the surveys differ is that they have different degrees of sample bias in terms of age distribution and, therefore, different degrees of sensitivity to the problem of incorrectly including obsolete capital in the estimate of potential capacity. The CEA designed its sample more than a decade ago, and has not updated it since, thereby generating a clear sample bias toward old enterprises. While GKS does update its sample every year, its choice of 43 representative goods and the share of these goods in total output have not been updated. The industry register from which the REB sample is drawn is updated only every five-seven

than some higher unsustainable short-run maximum that can be achieved only by postponing routine maintenance or temporarily boosting overtime to produce above capacity, because the latter will be inflationary.

35 This is similar to the U.S. Institute of Supply Management's definition of capacity utilization as the ratio of current output to "normal capacity," where the definition of normal capacity is left to the respondent (Morin and Stevens, 2004a, p. 4).

${ }^{36}$ The IET and CEA surveys do not clearly define the concept of capacity utilization to respondents. In the absence of any other information, their respondents may be likely to use a definition similar to Rosstat's, especially if they are also part of the Rosstat survey. This is particularly likely for CEA, since the CEA questionnaires are sent as part of a package with Rosstat statistical forms.

${ }^{37}$ Another problem is that none of the surveys appear to include "small businesses," which are defined as enterprises with less than 100 employees that are not owned by other medium-sized or large enterprises, state, public or religious organizations, charities, or other funds. 
years and, therefore, has some bias toward old enterprises as well. The IET sample is the only one that is updated monthly and, therefore, does not seem to have an age bias. The age bias is likely to matter because older enterprises are more likely to have technically or economically obsolete capital. To the extent that some capital is technically obsolete, that is, it can no longer produce output, survey respondents likely do not consider this capital as part of their capacity; hence, this should not affect the reported capacity utilization rate. However, it is also likely that part of the capital stock is economically obsolete, which means that it can be used only to produce output for which there is no longer any demand (for example, because it is out of fashion or constitutes an input for another good that is no longer produced, or because it is simply much less efficient in producing a good for which there is still demand). ${ }^{38}$ In this case, survey respondents may incorrectly take this economically obsolete capital into account in estimating the potential, maximum, or "normal" output they can produce, which would lead to an underestimation of the capacity utilization rate. Such underestimation is likely to be stronger the less frequently the sample is updated, which could provide another explanation why the CEA estimates are the lowest.

\section{A. Rosstat (GKS)}

\section{Sample frequency and size}

Rosstat (previously called Goskomstat; hence, the abbreviation GKS) publishes annual information on average capacity utilization rates for a limited number (43) of consumer, investment, and intermediate goods. ${ }^{39}$ Questionnaires are sent to all registered industrial enterprises in Russia (except small businesses and a few other exceptions), which are obliged to provide information on the production capacity for every good produced. The number of questionnaires used to calculate the published capacity utilization rates is estimated at roughly $7,000 .^{40}$ At the time of this study, annual data for each of the 43 goods were available for the period 1992-2003; the data for 2004 will only be released at end-2005 or the beginning of 2006.

\footnotetext{
${ }^{38}$ Real appreciation or an increase in disposable income can also lead to a fall in demand for low-quality, domestically produced goods, with consumers switching to higher-quality, imported substitutes. However, to the extent that this switch in demand may be temporary, the capital used to produce domestic, low-quality goods may not necessarily be considered economically obsolete. Enterprises should write off their economically obsolete capital, and no longer consider it part of their capacity, only if the switch in demand appears to be permanent.

39 The 43 goods are the ones for which Rosstat has published capacity utilization estimates since 1990; however, the sample has grown over time, and capacity utilization estimates are currently available for about 70-75 goods in the Rosstat publication "Russia in Figures." In fact, Rosstat appears to have capacity utilization estimates for as many as 600 goods, but it does not publish these estimates.

40 This is only a rough estimate, and is obtained by multiplying the share of the sampled goods in total industrial output, as estimated by Bessonov, by the total number of industrial enterprises (except small businesses), as reported by Rosstat. Note that there could be some double counting, in that some enterprises may be producing more than 1 out of the group of 43 goods.
} 
While Rosstat itself does not publish an overall capacity utilization estimate for industry as a whole, such an estimate is provided by Vladimir Bessonov of the Higher School of Economics (e.g., Bessonov, 2004).

\section{Representativeness of the sample}

The representativeness of Rosstat's sample depends on how representative the selected 43 goods are of the Russian economy, that is, whether the enterprises producing these goods have, on average, the same degree of capacity utilization as industry as a whole. Rosstat could not provide any information in this regard, other than to indicate that the 43 goods were selected in agreement with the Ministry of Economic Development and Trade on the basis of their "economic importance." Most likely, this means that the 43 goods were the ones that had the largest shares in nominal industrial output at the time they were selected. If this is the case, then there is no guarantee that the enterprises producing these goods are representative in terms of their capacity utilization rate. While GKS does update its sample every year, its choice of 43 representative goods and the share of these goods in total output have not been updated.

For each of the 43 goods, Rosstat calculates the capacity utilization rate by dividing aggregate actual output by aggregate production capacity, where the aggregates are taken over all surveyed enterprises that produce a given good. Bessonov further aggregates Rosstat's capacity utilization estimates to obtain an overall capacity utilization estimate for industry as a whole. The aggregation is done by weighting the capacity utilization estimate for each good by the share of each good in actual industrial output in 1995. Since the shares of 6 goods in total industrial output were negligible in 1995, Bessonov included only 37 out of 43 goods in his aggregation. While the inclusion or exclusion of goods with negligible shares is unlikely to affect the representativeness of the results, the fact that weights from 1995 are used could create some bias to the extent that the share of certain goods may have fallen or risen over time. For example, it is possible that certain goods have become obsolete (e.g., because superior substitutes have become available) in which case the output share of these goods has declined over time. Most likely, this also means that the capacity utilization rate of the enterprises producing these goods has fallen (since capacity typically does not decline as rapidly as actual output). By nevertheless applying the historically larger output share of these goods, the corresponding enterprises are overrepresented in the sample, and therefore the overall capacity utilization rate may be underestimated. ${ }^{41}$

\section{Survey questions}

Enterprises are asked to fill out a statistical form in which, for every good produced, the following indicators should be reported for a given year:

\footnotetext{
${ }^{41}$ While it would be preferable to weight each good by its share in current output, Bessonov refrained from doing so because the output shares estimated for 1998 and 1999, around the time of the financial crisis, seemed unreliable.
} 
- $\quad$ actual output produced during the year;

- $\quad$ production capacity at the beginning of the year (as a rule, equal to the production capacity at the end of the previous year, as reported a year earlier);

- $\quad$ production capacity at the end of the year, calculated as the production capacity at the beginning of the year plus total net increase in production capacity;

- increases in production capacity by cause: expansion, reconstruction, renovation, equipment rental, change in the type of good produced (decrease in labor intensity), other factors;

- decreases in production capacity by cause: change in the type of good produced (increase in labor intensity), depreciation, equipment rental, and other factors;

- $\quad$ average production capacity during the year, calculated as the production capacity at the beginning of the year plus the average annual increase in production capacity minus the average annual decrease in production capacity; ${ }^{42}$ and

- utilization of average production capacity during the year (in percent), calculated as the ratio of average actual output to average production capacity.

The terms "capacity utilization rate" and "production capacity" are defined as follows:

- Capacity utilization rate. The capacity utilization rate for a given good is defined as the ratio of actual annual output to the average annual "production capacity" of the enterprises that produce this good, where the latter is defined below.

- $\quad$ Production capacity. Production capacity is defined as the maximum possible level of output (per year, day, or shift). It is determined on the basis of the maximum utilization of capacity and production space, given a normal operating cycle (e.g., excluding overtime). Industry-specific instructions are given to define production capacity more specifically for each industry.

\footnotetext{
${ }^{42}$ The average annual increase (or decrease) in production capacity is calculated by aggregating annual increases (or decreases) by cause, weighted by the period of time (in percent of the year) during which this cause was effective. As an exception, increases or decreases due to changes in labor intensity are added without weighting.
} 


\section{Relevant indicators}

As mentioned earlier, Rosstat publishes its estimate of the average capacity utilization rate for each of the 43 goods, according to the definition above, while Bessonov publishes an aggregate capacity utilization estimate for industry as a whole.

\section{B. The Institute for the Economy in Transition (IET)}

\section{Sample frequency and size}

The Institute for the Economy in Transition has conducted surveys since March 1992 on the basis of European-harmonized questionnaires. Questions related to capacity and labor utilization are asked on a quarterly basis, and the results are published in the Russian Bulletin of Business Cycle Surveys (see, e.g., IET, 2004).

The sample comprises approximately 1,200 industrial enterprises (of which currently 9 enterprises are in the fuel sector). The response rate amounts to 65-70 percent, implying that approximately 800 enterprises participate in each round.

\section{Representativeness of the sample}

The IET's starting point is the Industrial Enterprises Register. The enterprises from this list are divided into 16 industrial sectors, according to the official industrial classification system (OKOHX) that was in force until December 31, 2004. ${ }^{43}$ The IET sample takes 14 out of these 16 industrial sectors, eliminating the microbiological industry and the category "other industries." The IET has somewhat fewer subsectors than the official classification system, as it merges some of them into a common category (e.g., ferrous and nonferrous metallurgy). The resulting IET sample contains 14 industrial sectors and 61 subsectors.

By taking into account size distribution both in the sample design and in the averaging of responses, the IET sample appears to put too much weight on large enterprises. For each of the 61 subsectors, the IET sample includes all ${ }^{44}$ large enterprises (with more than 500 employees), half of all medium-sized enterprises (100-500 employees), and one-third of all smaller enterprises (those with less than 100 employees, but not including so-called small businesses). If this sample distribution were to correspond to the population distribution (in terms of capacity), which is presumably the goal, then an unbiased estimate could be obtained by taking an unweighted average of enterprise responses. However, the IET computes a weighted average of enterprise responses, using enterprise employment as

\footnotetext{
${ }^{43}$ On January 1, 2005, Rosstat switched to a new industrial classification system (ОКВЭД), and the statistics based on this new system have been revised back to 2003.

${ }^{44}$ Except Gazprom.
} 
weights, as a result of which large enterprises are overrepresented in the calculation of the average capacity utilization rate (see Table A2).

Unlike the other surveys, the IET sample is not biased toward old enterprises. The sample is updated monthly to replace up to 50 nonresponding and closed enterprises with new ones.

\section{Survey questions}

The IET questionnaire contains three questions related to capacity and labor utilization:

- What is the current capacity utilization rate of your enterprise (in percent)? ${ }^{45}$

- How would you assess, relative to expected demand,

(a) your available production capacity (excessive, sufficient, insufficient)?

(b) your current number of employees (excessive, sufficient, insufficient)?

- What currently is the main obstacle for production growth at your enterprise?

Any number of the following answers can be chosen:

(a) nothing; (b) domestic demand; (c) low export demand; (d) competition with imports; (e) nonpayments of buyers; (f) lack of working capital; (g) lack of qualified workers; (h) lack of equipment; (i) lack of raw materials and semi manufactures; (j) lack of energy resources; and $(\mathrm{k})$ other.

The questionnaire does not define the term "capacity utilization rate," nor does it define any other technical terms.

\section{Relevant indicators}

Based on the answers to the three questions above, the IET constructs several indicators related to capacity and labor utilization. It publishes these indicators both for industry as a whole and for seven separate industries. ${ }^{46}$ The indicators are the following:

\footnotetext{
${ }^{45}$ Until July 2001, this question had been formulated in a more restrictive way, by asking respondents to choose from eight categories $(<30 ; 30-40 ; 41-50 ; 51-60 ; 61-70 ; 71-80 ; 81-90$; and $>90)$. The formulations of the other questions have remained unchanged since 1996.

${ }^{46}$ The seven industries are (1) ferrous and nonferrous metals; (2) chemical and petrochemical; (3) machinery and metalwork; (4) forestry, woodworking, pulp and paper; (5) construction materials; (6) light industry; and (7) the food industry. Estimates of capacity utilization are published only for six industries (the ones mentioned
} 
- $\quad$ capacity utilization rate: the average answer to the first question, weighted by employment;

- the share of enterprises with excessive capacity/labor: the share of respondents who answered "excessive" to the second question (parts a and b, respectively);

- the share of enterprises with insufficient capacity/labor: the share of respondents who answered "insufficient" to the second question (parts a and b, respectively);

- the balance of capacity/labor assessments: the share of enterprises with excessive capacity/labor minus the share of enterprises with insufficient capacity/labor; and

- the frequency of mentioning lack of equipment/qualified workers as a main obstacle to growth: the share of respondents who chose either "lack of equipment" or "lack of qualified workers" as an answer to the third question.

\section{Russian Economic Barometer (REB)}

\section{Sample frequency and size}

Since December 1991, the Institute of World Economy and International Relations of the Russian Academy of Science has been conducting panel surveys of Russian enterprise managers, which are published in the bulletin Russian Economic Barometer. The surveys are conducted on a monthly basis, although some questions are asked only on a quarterly basis. Capacity utilization estimates are available from December 1991 onward, while labor utilization estimates are available from January 1994 onward.

The REB sample consists of around 500 enterprises that respond regularly, of which 150-220 enterprises respond in any given month. The response rate is thus estimated at 30-40 percent (REB, 2004).

\section{Representativeness of the sample}

The REB sample is constructed as the set of 500 enterprises that regularly respond to questionnaires that are sent out at random to 1,000 out of a long list of registered enterprises. The sample of 500 enterprises is continuously updated, as those enterprises that respond are sent a questionnaire again the next month, while those that do not respond the first time they receive a questionnaire are not sent any further questionnaires. However, the list of 30,00040,000 enterprises from which random drawings are made is updated only once every fiveseven years, when REB purchases a new version of the register. As a result, the REB sample may somewhat overrepresent older enterprises. 
While the sample is essentially random, some selection bias may be present if the probability that an enterprise responds is correlated with its capacity utilization rate. For example, enterprises with lower capacity utilization rates may be more likely to respond because they have more time available to respond to surveys. According to REB's Program Director, Sergei Aukutsionek, there is some evidence of such a selection bias, as the response rate of the REB survey was significantly higher during the crisis period, when capacity utilization rates were low. If such a selection bias is indeed present, then capacity utilization may be underestimated. However, this cannot explain the systematic differences between surveys, because a similar selection bias would be present in the other surveys as well.

Even if the REB sample were truly random, its small sample size implies that it underestimates the share of large enterprises, and overestimates the share of small enterprises, relative to the population of all registered industrial enterprises. As Table A2 shows, the share of small (defined here as those enterprises with less than 500 employees) is almost 60 percent in the REB sample, while this same share is only around 40 percent in the "population" of all registered industrial enterprises. ${ }^{47}$ Similarly, the share of large enterprises (with more than 1,000 employees) is only 22 percent in the REB sample-half of that in the population. ${ }^{48}$ The most likely explanation for this is that, even though large enterprises constitute a large share of the distribution in terms of the number of employees, the number of large enterprises is much lower than the number of small enterprises. Therefore, a sample with a small sample size, such as the REB, is less likely to include such large enterprises in any given "drawing." 49 If the sample size were to be increased, this small-sample bias would gradually disappear, and, as long as sampling remained random, the sample distribution would approach the population distribution.

An additional reason why the REB sample overrepresents small enterprises is that it averages enterprise responses without weighting them by size. As noted, random sampling requires that responses be weighted by capacity shares (which can be proxied by output or employment shares) when calculating the sample average. By not doing so, the REB implicitly assumes that each enterprise has an equal impact on average capacity utilization,

\footnotetext{
${ }^{47}$ The population of all registered enterprises is the set of enterprises on the basis of which Rosstat calculates official industrial statistics for the Russian economy. This is by no means the same as the Rosstat sample that is used for capacity utilization estimates, discussed in Section A above.

${ }^{48}$ Nevertheless, the REB sample does contain a number of reasonably large enterprises, given that, among the 20 percent of enterprises with more than 1,000 employees, one-fourth has more than 2,000 employees, and the average number of employees in this group is roughly 3,000 (REB, 2004, Table 2).

${ }^{49}$ To see this, assume for simplicity that the population consists of 999 small enterprises, employing 50 percent of all employees, and 1 very large enterprise, employing the other 50 percent of employees. Taking a random sample with a very small sample size — say, a sample size of one - would imply that, on average, once every 1,000 times the sample is conducted, the sample will include the large enterprise. Thus, while the sample will be unbiased (in the sense that the expected enterprise size in the sample equals the average enterprise size in the population), 999 out of 1,000 times the sample will underestimate the share of large enterprises.
} 
while in reality those enterprises with a larger share in total capacity have a larger effect on capacity utilization in industry as a whole. As a result, smaller enterprises are overrepresented in the REB capacity utilization estimate, and larger enterprises are underrepresented.

\section{Survey questions}

The questions on capacity and labor utilization are formulated as follows:

Please assess the following indicators, relative to the normal level for the current season, assuming that the normal level is equal to 100 percent: (1) capacity utilization rate; (2) labor utilization rate.

The respondents are asked to choose from several possible answers, including "more than 120 percent." No further definition of the terms "capacity utilization" and "labor utilization" are given.

\section{Relevant indicators}

REB reports several survey-based indicators that are related to factor utilization:

- capacity utilization rate (in percent of the "normal monthly level");

- labor utilization rate (in percent of the "normal monthly level");

- capacity/labor redundancy: share of enterprises that consider their production capacity/labor "redundant" relative to expected demand during the next 12 months;

- $\quad$ capacity/labor insufficiency: share of enterprises that consider their production capacity/labor "insufficient" relative to expected demand during the next 12 months;

- balance of capacity/labor assessments: share of enterprises with redundant capacity/labor minus the share of enterprises with insufficient capacity/labor; and

- $\quad$ limits to production: shortage of labor or equipment (share of enterprises that mention this factor as one of the three most important ones out of a list of ten-twelve factors, including insufficient demand, a shortage of raw materials and semifinished products, and a shortage of financial resources).

The indicators of capacity and labor utilization are reported for industry as a whole, as well as for seven industries: ferrous and nonferrous metals, forestry, chemical and petrochemical, machinery and metalwork, construction materials, light industry, and food industry. While indicators for the fuel and electricity industries are not published, these industries are included in the calculation of the overall capacity utilization rate. 


\section{The Center for Economic Analysis (CEA)}

\section{Sample frequency and size}

The Center for Economic Analysis of the Government of the Russian Federation (Центр Экономической Конъюнктуры при Правительстве Российской Федерации) has been publishing monthly estimates of capacity utilization since 1993 . The sample comprises 1,400 industrial enterprises from all industrial sectors, including the fuel sector. The response rate is quite high, at 85 percent, with approximately 1,200 enterprises responding every month. This high response rate is likely because the CEA questionnaires are sent as part of a package of Rosstat statistical forms, which enterprises are obliged to fill out.

\section{Representativeness of the sample}

At first sight, the CEA sample appears representative in that its enterprise size distribution constitutes a very good approximation to the population size distribution (Table A2). Enterprise responses are aggregated without weighting them by size, which, indeed, is appropriate if the distribution of capacity in the sample corresponds to the distribution of capacity in the population.

Due to insufficient updating, however, the CEA sample is likely to overrepresent old enterprises. This bias toward old enterprises occurs because the CEA sample (panel) consists of those enterprises that produced, back in 1993-94, the largest share of output in a given industry (60-70 percent of output for most industries, and 40-50 percent of output for some other industries). This panel has basically remained unchanged since the time of its construction, as less than 1 percent of the originally selected enterprises are estimated to have disappeared from the sample, while no new enterprises have been added. ${ }^{50}$ Moreover, it is likely that, with increased competition, the market shares of enterprises that used to produce the majority of output in the early 1990s have declined over time, in which case these enterprises are particularly overrepresented.

The bias toward old enterprises implies that the capacity utilization rate is likely underestimated, which seems to be confirmed by the fact that the CEA has the lowest utilization rate estimates of all surveys. One reason for this underestimation is that old enterprises whose market shares have declined over time, and which are therefore overrepresented, are likely to have lower-than-average capacity utilization rates, because their utilized capacity may have fallen at a faster rate than their total capacity. A second reason is that older enterprises are likely to have accumulated more technically or

\footnotetext{
${ }^{50}$ However, following Rosstat's switch to a new industrial classification system in January 2005, the CEA has started expanding its current sample of 1,200 enterprises (those that respond), adding 3,300 to construct a new sample of 4,500 enterprises. The 1,200 old enterprises will remain part of the new sample only for a transition period.
} 
economically obsolete capital. ${ }^{51}$ While enterprises should not count such obsolete capital as part of their "productive capacity," according to the CEA it is likely that they nevertheless do so, in which case they underestimate their true capacity utilization rate.

\section{Survey questions}

The CEA questionnaire contains four questions related to capacity and labor utilization:

1. Utilization rate of productive capacity in the current month $(<30$ percent; $31-40$ percent; 41-50 percent; 51-60 percent; 61-70 percent; 71-80 percent; 81-90 percent; or $91-100$ percent.);

2. Sufficiency of productive capacities relative to expected demand in the nearest 12 months (excessive, sufficient, or insufficient).

3. Assessment of the number of employed in the current month relative to actual production volume (excessive, sufficient, or insufficient).

4. Obstacles to production growth. Any number of the following answers can be chosen:

(a) insufficient domestic demand for goods produced by the enterprise;

(b) insufficient external demand for goods produced by the enterprise;

(c) competing imports;

(d) high level of taxation;

(e) deterioration and lack of equipment;

(f) uncertain economic situation;

(g) high commercial credit interest rates;

(h) lack of financial resources;

(i) lack of qualified workers;

(j) lack or imperfectness of legislation; and

(k) no obstacles.

\footnotetext{
${ }^{51}$ Some evidence for this is provided by CEA estimates that the average service life of equipment is 20.7 years, while the share of new equipment (purchased in the last five-six years) is only 15 percent.
} 


\section{Relevant indicators}

The CEA reports capacity utilization rates for industry as a whole, as well as for the following industries: electricity, fuel, ferrous metals, nonferrous metals, forestry, chemical and petrochemical, machinery and metalwork, construction materials, light industry, and food industry. In addition, the CEA also publishes enterprises' assessments of the sufficiency of labor, the sufficiency of production capacity, and the obstacles to growth. 


\section{Econometric NAICU Estimates}

Table B1. NAICU Estimates based on REB Capacity Utilization Survey 1/

(Dependent variable: monthly change in core inflation)

\begin{tabular}{|c|c|c|c|c|c|c|c|c|c|}
\hline & Coeff. & S.E. & Prob. & Coeff. & S.E. & Prob. & Coeff. & S.E. & Prob. \\
\hline Constant & -5.70 & 2.17 & 0.01 & -3.91 & 1.09 & 0.00 & -3.33 & 0.77 & 0.00 \\
\hline $\mathrm{CU}$ & 0.08 & 0.03 & 0.02 & 0.05 & 0.02 & 0.00 & 0.04 & 0.01 & 0.00 \\
\hline NAICU & 74.38 & 1.24 & 0.00 & 75.24 & 1.27 & 0.00 & 74.27 & 0.90 & 0.00 \\
\hline$\Delta \pi_{\mathrm{t}-1}$ & & & & 0.67 & 0.09 & 0.00 & 0.63 & 0.06 & 0.00 \\
\hline$\Delta \pi_{\mathrm{t}-3}$ & & & & -0.24 & 0.12 & 0.06 & -0.23 & 0.09 & 0.01 \\
\hline$\Delta \pi_{\mathrm{t}-4}$ & & & & 0.30 & 0.12 & 0.02 & 0.37 & 0.09 & 0.00 \\
\hline$\Delta \pi_{\mathrm{t}-5}$ & & & & -0.34 & 0.10 & 0.00 & -0.38 & 0.08 & 0.00 \\
\hline$\Delta \pi_{\mathrm{t}-7}$ & & & & & & & 0.18 & 0.06 & 0.00 \\
\hline$\Delta \pi_{\mathrm{t}-12}$ & & & & -0.25 & 0.05 & 0.00 & -0.23 & 0.04 & 0.00 \\
\hline$\Delta \Delta \mathrm{m}_{\mathrm{t}-5}$ & & & & & & & -0.04 & 0.01 & 0.01 \\
\hline$\Delta \Delta \mathrm{m}_{\mathrm{t}-7}$ & & & & & & & 0.06 & 0.01 & 0.00 \\
\hline$\Delta \Delta \mathrm{e}_{\mathrm{t}-1}$ & & & & & & & 0.07 & 0.02 & 0.00 \\
\hline$\Delta \Delta \mathrm{e}_{\mathrm{t}-9}$ & & & & & & & -0.07 & 0.02 & 0.00 \\
\hline$\Delta \Delta \mathrm{oil}_{\mathrm{t}-2}$ & & & & & & & -0.02 & 0.01 & 0.02 \\
\hline Sample period & \multicolumn{3}{|c|}{$2000: 2-2005: 4$} & \multicolumn{3}{|c|}{ 2001:2-2005:4 } & \multicolumn{3}{|c|}{ 2001:2-2005:1 } \\
\hline No. of observations & \multicolumn{2}{|c|}{63} & & \multicolumn{2}{|c|}{51} & & \multicolumn{2}{|c|}{48} & \\
\hline R-squared & \multicolumn{2}{|l|}{0.09} & & \multicolumn{2}{|l|}{0.74} & & \multicolumn{2}{|l|}{0.92} & \\
\hline Adjusted R-squared & \multicolumn{2}{|l|}{0.08} & & \multicolumn{2}{|l|}{0.71} & & \multicolumn{2}{|l|}{0.89} & \\
\hline S.E. of regression & \multicolumn{2}{|l|}{0.78} & & \multicolumn{2}{|l|}{0.28} & & \multicolumn{2}{|l|}{0.18} & \\
\hline Log likelihood & \multicolumn{2}{|l|}{16.70} & & \multicolumn{2}{|l|}{68.40} & & \multicolumn{2}{|l|}{91.11} & \\
\hline Akaike info criterion & \multicolumn{2}{|l|}{-0.47} & & \multicolumn{2}{|l|}{-2.41} & & \multicolumn{2}{|l|}{-3.25} & \\
\hline HQ info criterion & \multicolumn{2}{|l|}{-0.44} & & \multicolumn{2}{|l|}{-2.31} & & \multicolumn{2}{|l|}{-3.06} & \\
\hline Schwartz info criterion & \multicolumn{2}{|l|}{-0.40} & & \multicolumn{2}{|l|}{-2.14} & & \multicolumn{2}{|l|}{-2.75} & \\
\hline F-stat & \multicolumn{2}{|l|}{6.24} & 0.02 & \multicolumn{2}{|l|}{21.37} & 0.00 & \multicolumn{2}{|l|}{33.57} & 0.00 \\
\hline AR $1-4$ test & 7.71 & & 0.00 & 0.94 & & 0.45 & 0.70 & & 0.60 \\
\hline ARCH 1-4 test & 16.74 & & 0.00 & 0.21 & & 0.93 & 0.79 & & 0.54 \\
\hline Normality test & 10.87 & & 0.00 & 7.26 & & 0.03 & 1.00 & & 0.61 \\
\hline
\end{tabular}

$1 /$ The explanatory variables include year-on-year core inflation $(\pi)$, broad money $(m)$, the nominal effective exchange rate ( $e$, where an increase is an appreciation), and the Urals oil price (oil). The symbol $\Delta$ indicates the monthly change in a variable, while the symbol $\Delta \Delta$ indicates the monthly change in the 12-month rate. 
Table B2. NAICU Estimates based on IET Capacity Utilization Survey 1/

(Dependent variable: monthly change in core inflation) 2/

\begin{tabular}{|c|c|c|c|c|c|c|c|c|c|}
\hline & Coeff. & S.E. & Prob. & Coeff. & S.E. & Prob. & Coeff. & S.E. & Prob. \\
\hline Constant & -3.70 & 1.48 & 0.02 & -3.51 & 0.72 & 0.00 & -3.03 & 0.59 & 0.00 \\
\hline $\mathrm{CU}$ & 0.06 & 0.02 & 0.03 & 0.05 & 0.01 & 0.00 & 0.05 & 0.01 & 0.00 \\
\hline NAICU & 64.62 & 2.98 & 0.00 & 65.29 & 1.20 & 0.00 & 65.56 & 1.03 & 0.00 \\
\hline$\Delta \pi_{\mathrm{t}-1}$ & & & & 0.50 & 0.08 & 0.00 & 0.48 & 0.06 & 0.00 \\
\hline$\Delta \pi_{\mathrm{t}-5}$ & & & & -0.25 & 0.07 & 0.00 & -0.30 & 0.07 & 0.00 \\
\hline$\Delta \pi_{\mathrm{t}-7}$ & & & & & & & 0.18 & 0.07 & 0.02 \\
\hline$\Delta \pi_{\mathrm{t}-12}$ & & & & -0.34 & 0.05 & 0.00 & -0.37 & 0.05 & 0.00 \\
\hline$\Delta \Delta \mathrm{m}_{\mathrm{t}-5}$ & & & & & & & -0.06 & 0.02 & 0.00 \\
\hline$\Delta \Delta \mathrm{m}_{\mathrm{t}-7}$ & & & & & & & 0.05 & 0.01 & 0.00 \\
\hline$\Delta \Delta \mathrm{m}_{\mathrm{t}-10}$ & & & & & & & -0.05 & 0.02 & 0.00 \\
\hline$\Delta \Delta \mathrm{e}_{\mathrm{t}-1}$ & & & & & & & 0.07 & 0.02 & 0.00 \\
\hline$\Delta \Delta \mathrm{e}_{\mathrm{t}-3}$ & & & & & & & 0.06 & 0.02 & 0.00 \\
\hline Sample period & \multicolumn{3}{|c|}{ 2000:2-2004:12 } & \multicolumn{2}{|c|}{ 2001:2-2004:12 } & & \multicolumn{2}{|c|}{ 2001:2-2004:12 } & \\
\hline No. of observations & \multicolumn{2}{|c|}{59} & & \multicolumn{2}{|c|}{47} & & \multicolumn{2}{|c|}{47} & \\
\hline R-squared & \multicolumn{2}{|l|}{0.08} & & \multicolumn{2}{|l|}{0.77} & & \multicolumn{2}{|l|}{0.90} & \\
\hline Adjusted R-squared & \multicolumn{2}{|l|}{0.07} & & \multicolumn{2}{|l|}{0.74} & & \multicolumn{2}{|l|}{0.87} & \\
\hline S.E. of regression & \multicolumn{2}{|l|}{0.81} & & \multicolumn{2}{|l|}{0.27} & & \multicolumn{2}{|l|}{0.19} & \\
\hline Log likelihood & \multicolumn{2}{|l|}{-69.96} & & \multicolumn{2}{|l|}{63.51} & & \multicolumn{2}{|l|}{83.61} & \\
\hline Akaike info criterion & \multicolumn{2}{|l|}{-0.40} & & \multicolumn{2}{|l|}{-2.49} & & \multicolumn{2}{|l|}{-3.09} & \\
\hline HQ info criterion & \multicolumn{2}{|l|}{-0.37} & & \multicolumn{2}{|l|}{-2.42} & & \multicolumn{2}{|l|}{-2.93} & \\
\hline Schwartz info criterion & \multicolumn{2}{|l|}{-0.33} & & \multicolumn{2}{|l|}{-2.29} & & \multicolumn{2}{|l|}{-2.66} & \\
\hline F-stat & \multicolumn{2}{|l|}{5.24} & 0.03 & \multicolumn{2}{|l|}{34.32} & 0.00 & \multicolumn{2}{|l|}{32.55} & 0.00 \\
\hline AR 1-4 test & \multicolumn{2}{|l|}{7.14} & 0.00 & 1.71 & & 0.17 & 1.06 & & 0.39 \\
\hline ARCH 1-4 test & 14.91 & & 0.00 & 0.35 & & 0.84 & 1.72 & & 0.17 \\
\hline Normality test & 12.42 & & 0.00 & 1.14 & & 0.56 & 0.63 & & 0.73 \\
\hline
\end{tabular}

1/ The explanatory variables include year-on-year core inflation $(\pi)$, broad money $(\mathrm{m})$, the nominal effective exchange rate (e, where an increase is an appreciation), and the Urals oil price (oil). The symbol $\Delta$ indicates the monthly change in a variable, while the symbol $\Delta \Delta$ indicates the monthly change in the 12-month rate.

$2 /$ The quarterly IET estimates of capacity utilization were interpolated to obtain monthly estimates, by assuming that capacity utilization within each quarter was unchanged. 
Table B3. NAICU Estimates based on CEA Capacity Utilization Survey 1/

(Dependent variable: monthly change in core inflation)

\begin{tabular}{|c|c|c|c|c|c|c|c|c|c|}
\hline & Coeff. & S.E. & Prob. & Coeff. & S.E. & Prob. & Coeff. & S.E. & Prob. \\
\hline Constant & -5.42 & 1.66 & 0.00 & -5.38 & 0.98 & 0.00 & -4.51 & 0.84 & 0.00 \\
\hline $\mathrm{CU}$ & 0.10 & 0.03 & 0.00 & 0.09 & 0.02 & 0.00 & 0.08 & 0.02 & 0.00 \\
\hline NAICU & 56.47 & 1.48 & 0.00 & $\mathbf{5 7 . 5 0}$ & 0.63 & 0.00 & 57.23 & 0.53 & 0.00 \\
\hline$\Delta \pi_{\mathrm{t}-1}$ & & & & 0.46 & 0.08 & 0.00 & 0.38 & 0.08 & 0.00 \\
\hline$\Delta \pi_{\mathrm{t}-2}$ & & & & & & & 0.17 & 0.09 & 0.07 \\
\hline$\Delta \pi_{\mathrm{t}-5}$ & & & & -0.28 & 0.07 & 0.00 & -0.30 & 0.06 & 0.00 \\
\hline$\Delta \pi_{\mathrm{t}-7}$ & & & & & & & 0.14 & 0.06 & 0.03 \\
\hline$\Delta \pi_{\mathrm{t}-12}$ & & & & -0.38 & 0.05 & 0.00 & -0.35 & 0.04 & 0.00 \\
\hline$\Delta \Delta \mathrm{m}_{\mathrm{t}-5}$ & & & & & & & -0.05 & 0.01 & 0.00 \\
\hline$\Delta \Delta \mathrm{m}_{\mathrm{t}-7}$ & & & & & & & 0.06 & 0.01 & 0.00 \\
\hline$\Delta \Delta \mathrm{m}_{\mathrm{t}-10}$ & & & & & & & -0.02 & 0.01 & 0.09 \\
\hline$\Delta \Delta \mathrm{e}_{\mathrm{t}-1}$ & & & & & & & 0.05 & 0.02 & 0.01 \\
\hline$\Delta \Delta \mathrm{e}_{\mathrm{t}-4}$ & & & & & & & 0.03 & 0.02 & 0.06 \\
\hline$\Delta \Delta \mathrm{e}_{\mathrm{t}-9}$ & & & & & & & -0.05 & 0.02 & 0.00 \\
\hline$\Delta \Delta$ oil $_{\mathrm{t}-2}$ & & & & & & & -0.01 & 0.01 & 0.04 \\
\hline Sample period & \multicolumn{3}{|c|}{ 2000:2-2004:12 } & \multicolumn{2}{|c|}{ 2001:2-2004:12 } & & \multicolumn{2}{|c|}{ 2001:2-2004:12 } & \\
\hline No. of observations & \multicolumn{2}{|c|}{59} & & \multicolumn{2}{|c|}{47} & & \multicolumn{2}{|c|}{47} & \\
\hline R-squared & \multicolumn{2}{|l|}{0.14} & & \multicolumn{2}{|l|}{0.79} & & \multicolumn{2}{|l|}{0.92} & \\
\hline Adjusted R-squared & \multicolumn{2}{|l|}{0.13} & & \multicolumn{2}{|l|}{0.77} & & \multicolumn{2}{|l|}{0.89} & \\
\hline S.E. of regression & \multicolumn{2}{|l|}{0.78} & & \multicolumn{2}{|l|}{0.26} & & \multicolumn{2}{|l|}{0.18} & \\
\hline Log likelihood & \multicolumn{2}{|l|}{-68.00} & & \multicolumn{2}{|l|}{65.99} & & \multicolumn{2}{|l|}{88.29} & \\
\hline Akaike info criterion & \multicolumn{2}{|l|}{-0.47} & & \multicolumn{2}{|l|}{-2.60} & & \multicolumn{2}{|l|}{-3.16} & \\
\hline HQ info criterion & \multicolumn{2}{|l|}{-0.44} & & \multicolumn{2}{|l|}{-2.52} & & \multicolumn{2}{|l|}{-2.95} & \\
\hline Schwartz info criterion & \multicolumn{2}{|l|}{-0.39} & & \multicolumn{2}{|l|}{-2.40} & & \multicolumn{2}{|l|}{-2.61} & \\
\hline F-stat & \multicolumn{2}{|l|}{9.53} & 0.00 & \multicolumn{2}{|l|}{39.31} & 0.00 & \multicolumn{2}{|l|}{28.56} & 0.00 \\
\hline AR 1-4 test & 7.32 & & 0.00 & 1.35 & & 0.27 & 1.50 & & 0.23 \\
\hline ARCH 1-4 test & 16.39 & & 0.00 & 1.18 & & 0.34 & 0.80 & & 0.54 \\
\hline Normality test & 10.77 & & 0.00 & 0.84 & & 0.66 & 0.62 & & 0.73 \\
\hline
\end{tabular}

$1 /$ The explanatory variables include year-on-year core inflation $(\pi)$, broad money $(\mathrm{m})$, the nominal effective exchange rate (e, where an increase is an appreciation), and the Urals oil price (oil). The symbol $\Delta$ indicates the monthly change in a variable, while the symbol $\Delta \Delta$ indicates the monthly change in the 12-month rate. 


\section{Statistical Methods for Estimating the Output Gap}

This Appendix discusses the technical details behind the construction of our statistical output gap measures, and describes the advantages and disadvantages of each method.

\section{A. Arithmetic Trend Fitting}

Perhaps the easiest way to measure the output gap is define it as the deviation between actual output and its trend, where the trend is then interpreted as the path for potential output. It seems most natural to assume an exponential trend, because this implies a constant growth rate. However, we also estimate linear and quadratic trends in order to allow for possible changes in the growth rate over time.

The trends are defined as follows:

- $\quad$ linear trend:

$$
y^{*}=a+b x
$$

- $\quad$ quadratic trend:

$$
y^{*}=a+b x+c x^{2} ; \text { and }
$$

- $\quad$ exponential trend:

$$
y^{*}=a^{*} \exp (b x) \text {. }
$$

\section{B. Univariate Statistical Filtering}

In this paper, we use two univariate statistical filters: the Hodrick-Prescott filter and the Christiano-Fitzgerald filter.

The Hodrick-Prescott (HP) filter is a popular smoothing method that is widely used in macroeconomics to obtain a smooth estimate of the long-term trend component of a series. The method was first used in a working paper (circulated in the early 1980s and published in 1997) by Hodrick and Prescott to analyze postwar U.S. business cycles.

The Hodrick-Prescott (HP) filter is a two-sided linear filter that minimizes the squared distance between actual output $(y)$ and potential output $\left(y^{*}\right)$, subject to a penalty that constrains the variation of potential output over time. That is, the HP filter sets $y^{*}$ so as to minimize

$$
\sum_{t=1}^{T}\left(y_{t}-y_{t}^{*}\right)^{2}+\lambda \sum_{t=2}^{T-1}\left(\left(y_{t+1}^{*}-y_{t}^{*}\right)-\left(y_{t}^{*}-y_{t-1}^{*}\right)\right)^{2}
$$


The "penalty parameter" $\lambda$ can be varied so that the larger $\lambda$, the less variation in $y$, that is, the smoother the potential output series. As $\lambda \rightarrow \infty$, the HP-filtered series approaches a linear trend.

Following Hodrick and Prescott (1997), it is standard practice to set $\lambda=1,600$ for quarterly data (and $\lambda=100$ for annual data, and $\lambda=14,400$ for monthly data). However, we also estimated the HP filter for lower values of $\lambda$ (400 and 100) since in Russia some part of output fluctuations may be structural rather than cyclical, and therefore should not necessarily be smoothed to the same extent as they are for advanced economies.

An important drawback of the HP filter is that it is subject to end-sample bias, owing to the symmetric treatment of the trending across the sample and the different constraints that apply within the sample and at its ends. In the equation above, the summation bounds are different for the first and second term, because the second difference of the trend is not defined around the first and the final observation. One way to deal with this bias in practice is to extend the observation period by adding a number of forecasts.

The Christiano-Fitzgerald (CF) filter is a band-pass frequency filter that is used to isolate the cyclical component of a time series by specifying a range for its duration. Roughly speaking, the band-pass filter is a linear filter that takes a two-sided weighted moving average of the data where cycles in a "band," given by a specified lower and upper bound, are "passed" through, or extracted, and the remaining cycles are filtered out (Christiano and Fitzgerald, 2003).

Using the CF filter requires us to specify the range of durations (periodicities) to pass through. Assuming that the business cycle in Russia can last from 1.5 to 8 years, we use 6 quarters for the lower duration, and 32 quarters for the upper duration.

We use the full sample asymmetric form of the CF filter, which is the most general form. It is time varying, in that the weights on leads and lags change for each observation, depending on the data. The alternative, using a fixed-length filter (such as the Baxter-King filter) would require that we use same number of lead and lag terms for every weighted moving average. This would imply that we would lose observations from both the beginning and the end of the original sample. The asymmetric filter, however, does not have this requirement and can be computed to the ends of the original sample. 


\section{References}

Andrienko, Yuri, and Sergei Guriev, 2004, "Determinants of Interregional Labor Mobility in Russia: Evidence from Panel Data," Economics of Transition, 2004, Vol. 12, No. 1, pp. 1-27.

Aukutsionek, Sergei, 2003, "Production Capacity of Russian Enterprises" (in Russian), Voprosy Ekonomiki, No. 5, pp. 121-35.

Baxter, Marianne, and Dorsey D. Farr, 2005, "Variable Capital Utilization and International Business Cycles," Journal of International Economics, Vol. 65, pp. 335-47.

Bessonov, Vladimir, 2004, "On the Dynamics of Total Factor Productivity in the Russian Transition Economy" (in Russian), Economic Journal of the Higher School of Economics, Vol. 8, No. 4, pp. 542-87.

Billmeier, Andreas, 2004a, "Ghostbusting: Which Output Gap Measure Really Matters?" IMF Working Paper 04/146 (Washington: International Monetary Fund). , 2004b, "Measuring a Roller Coster: Evidence on the Finnish Output Gap,” IMF Working Paper 04/57 (Washington: International Monetary Fund).

Bils, Mark, and Jang-Ok Cho, 1994, "Cyclical Factor Utilization," Journal of Monetary Economics, Vol. 33, pp. 319-54.

Blanchard, Olivier Jean, and Stanley Fischer, 1989, Lectures on Macroeconomics (Cambridge, Massachusetts: MIT Press).

Burnside, Craig, and Martin Eichenbaum, 1996, "Factor Hoarding and the Propagation of Business Cycle Shocks," American Economic Review, Vol. 86, No. 5, pp. 1154-74.

Bragin, V.A., and V.V. Osakovsky, 2004, "Estimate of the Natural Rate of Unemployment in the Russian Federation during 1994-2003: Empirical Analysis" (in Russian), Voprosy Ekonomiki, No. 3, pp. 95-104.

Christiano, Lawrence J., and Terry J. Fitzgerald, 2003, “The Band Pass Filter," International Economic Review, Vol. 44, No. 2, pp. 435-65.

Corrado, C., and J. Mattey, 1997, "Capacity Utilization," Journal of Economic Perspectives, Vol. 11, No. 1, pp. 151-67.

Dolinskaya, Irina, 2001, “Explaining Russia's Output Collapse: Aggregate Sources and Regional Evidence,” IMF Working Paper 01/16 (Washington: International Monetary Fund). 
Eatwell, John, 1997, "Effective Demand and Disguised Unemployment," in Employment and Economic Performance: Jobs, Inflation, and Growth, ed. by J. Michie and J. Smith (Oxford: Oxford University Press).

Emery, M. E., and C.-P. Chang, 1997, "Is There a Stable Relationship Between Capacity Utilization and Inflation?" Economic Review, Federal Reserve Bank of Dallas, First Quarter, pp. 14-20.

Franz, W., and R. J. Gordon, 1993, "German and American Wage and Price Dynamics," European Economic Review, Vol. 37, pp. 719-61.

Friedman, Milton, 1968, "The Role of Monetary Policy," American Economic Review, Vol. 58 (March), pp. 1-17.

Garner, A. C., 1994, “Capacity Utilization and U.S. Inflation,” Economic Review, Federal Reserve Bank of Kansas City, Vol. 74, No. 4, pp. 5-21.

Gavrilenkov, Evgeny, 2003, "Diversification of the Russian Economy and Growth," Discussion Paper No. 111 (Wuppertal, Germany: European Institute for International Economic Relations, University of Wuppertal)

Gordon, R. J., 1997, "The Time-Varying NAIRU and Its Implications for Economic Policy," Journal of Economic Perspectives, Vol. 11 (Winter), pp. 11-32.

Greenwood, Jeremy, Zvi Hercowitz, and Gregory W. Huffman, 1988, "Investment, Capacity Utilization, and the Real Business Cycle," American Economic Review Vol. 78, No. 3, pp. 402-17.

Hodrick, R. J., and E. C. Prescott, 1997, "Postwar U.S. Business Cycles: An Empirical Investigation," Journal of Money, Credit, and Banking, Vol. 29 (February), pp. 1-16.

IET, 2004, Russian Bulletin of Business Cycle Surveys (in Russian), various issues (Moscow, Russia: Institute for the Economy in Transition).

Kwon, Goohoon, and Antonio Spilimbergo, 2005, "Russia’s Regions: Income Volatility, Labor Mobility, and Fiscal Policy,” IMF Working Paper 05/185 (Washington: International Monetary Fund).

Lissovolik, Yaroslav, 2004, “Doubling GDP: Putin’s Mission Impossible” (Moscow: United Financial Group).

McElhattan, R., 1978, "Estimating a Stable Inflation Rate of Capacity Utilization,” Economic Review, Federal Reserve Bank of San Francisco, Fall, pp. 20-30. , 1985, "Inflation, Supply Shocks, and the Stable Inflation Rate of Capacity Utilization," Economic Review, Federal Reserve Bank of San Francisco, Winter, pp. 45-63. 
Morin, Norman, and John Stevens, 2004a, "Diverging Measures of Capacity Utilization," Finance and Economics Discussion Series No. 2004-58 (Washington: Federal Reserve Board, Divisions of Research \& Statistics and Monetary Affairs).

Morin, Norman, and John Stevens, 2004b, "Estimating Capacity Utilization from Survey Data," Finance and Economics Discussion Series No. 2004-49 (Washington: Federal Reserve Board, Divisions of Research \& Statistics and Monetary Affairs).

Moscow Narodny Bank, 2004, "MNB Manufacturing PMI” and "MNB Services PMI," various issues.

Nahuis, Niek J., 2003, “An Alternative Demand Indicator: The 'Non-Accelerating Inflation Rate of Capacity Utilization'," Applied Economics, Vol. 35, No. 11, pp. 1339-44.

Oomes, Nienke, and Franziska Ohnsorge, 2005, "Money Demand and Inflation in Dollarized Economies: The Case of Russia," Journal of Comparative Economics, Vol. 33, No. 3, pp. 462-83 (also published as IMF Working Paper 05/144, July 2005).

Romer, David, 2001, Advanced Macroeconomics (New York: McGraw-Hill).

Russian Economic Barometer, 2004, "Outline of REB Surveys," Russian Economic Barometer, Vol. 13, No. 4, pp. 38-40.

Staiger, D., J. H. Stock, and M. Watson, 1997, “The NAIRU, Unemployment, and Monetary Policy," Journal of Economic Perspectives, Vol. 11 (Winter), pp. 33-49. 